Please do not remove this page

RMIT

UNIVERSITY

\title{
Test section streaks originating from imperfections in a zither located upstream of a contraction
}

Pook, David; Watmuff, Jonathan; Orifici, Adrian

https://researchrepository.rmit.edu.au/esploro/outputs/9921862743801341/filesAndLinks?institution=61RMIT_INST\&index=null

Pook, D., Watmuff, J., \& Orifici, A. (2016). Test section streaks originating from imperfections in a zither located upstream of a contraction. Journal of Fluid Mechanics, 787, 254-291.

https://doi.org/10.1017/jfm.2015.658

Document Version: Published Version

Published Version: https://doi.org/10.1017/jfm.2015.658

Repository homepage: https://researchrepository.rmit.edu.au

(C) Cambridge University Press 2015

Downloaded On 2023/04/27 00:46:22 +1000

Please do not remove this page 
Thank you for downloading this document from the RMIT Research Repository.

The RMIT Research Repository is an open access database showcasing the research outputs of RMIT University researchers.

RMIT Research Repository http://researchbank.rmit.edu.au/

\section{Citation:}

Pook, D, Watmuff, J and Orifici, A 2016, 'Test section streaks originating from imperfections in a zither located upstream of a contraction', Journal of Fluid Mechanics, vol. 787, pp. 254-291.

See this record in the RMIT Research Repository at: https://researchbank.rmit.edu.au/view/rmit:34593

Version: Published Version

Copyright Statement: (C) Cambridge University Press 2015

Link to Published Version:

http://dx.doi.org/10.1017/jfm.2015.658 


\title{
Test section streaks originating from imperfections in a zither located upstream of a contraction
}

\author{
David A. Pook ${ }^{1} \dagger$, Jonathan H. Watmuff ${ }^{1}$ and Adrian C. Orifici ${ }^{1}$ \\ ${ }^{1}$ School of Aerospace, Mechanical and Manufacturing Engineering, RMIT University, \\ Bundoora, VIC 3083, Australia
}

(Received 20 October 2014; revised 13 October 2015; accepted 3 November 2015)

\begin{abstract}
Defining a link between wind-tunnel settling chamber screens, flow quality and test section boundary-layer spanwise variation is necessary for accurate transition prediction. The aim of this work is to begin establishing this link. The computed, steady, laminar wake of a zither (screen model) with imperfect wire spacing is tracked through a contraction and into a model test section. The contraction converts the zither wake into streamwise vorticity which then creates spanwise variation (streaks) in the test-section boundary layer. The magnitude of the spanwise variation is sensitive to the zither open-area ratio and imperfections, but the observed wavelength is relatively insensitive to the zither wire spacing. Increased spanwise variation is attributed to large wavelength variation of drag across the zither, and not the coalescence of jets phenomena. The linear stability of the streaks is predicted using the parabolized stability equations with the $\mathrm{e}^{N}$ method. A standard deviation of zither wire position error of $38.1 \mu \mathrm{m}$ ( $15 \%$ of wire diameter) for a zither of $50 \%$ open-area ratio is found to suppress Tollmien-Schlichting wave growth significantly.
\end{abstract}

Key words: boundary layers, boundary layer stability, wakes

\section{Introduction}

Thirty-five years ago, Morkovin (1979) summarised observations of streamwise vorticity in boundary layers and the absence of a causative condition, although an empirical link to wind-tunnel settling chamber screens had been established. Experiments on nominally two-dimensional flows in wind tunnels cannot be assumed to be two-dimensional. Streamwise vorticity generates spanwise variation (streaks) that can significantly alter the boundary-layer properties and stability characteristics. At elevated free-stream turbulence (FST) levels, the streaks are called Klebanoff streaks and transition to turbulence is often via a bypass mechanism (see Zaki 2013; Goldstein 2014 for recent reviews). However, even at low FST levels, significant spanwise variation and streaks can be observed in some experiments.

$†$ Email address for correspondence: d.pook.engineer@gmail.com 


\subsection{Observations of boundary-layer spanwise variation}

Spanwise boundary-layer variation can manifest in differing ways. The spanwise spacing of Görtler vortices has been linked to the free stream (Swearingen \& Blackwelder 1987), while early boundary-layer transition studies noted significant spanwise variation (Klebanoff, Tidstrom \& Sargent 1961). Advances have shown this to be a secondary instability of the Tollmien-Schlichting (TS) wave (Herbert 1988), although weak streaks can affect the spanwise scale and secondary instability growth rate, delaying or promoting transition (Liu, Zaki \& Durbin 2008b). The simulations of Schlatter et al. (2011) provide a graphical demonstration.

Klebanoff streaks, often associated with elevated FST levels (Klebanoff 1971; Kendall 1985; Westin et al. 1994; Kendall 1998; Watmuff 1998; Matsubara \& Alfredsson 2001; Fransson, Matsubara \& Alfredsson 2005b; Nolan \& Walsh 2012), are a form of spanwise variation that can influence transition involving TS waves. Boiko et al. (1994) observed forced TS wave growth to be reduced by Klebanoff streaks, although transition shifted upstream. However, Watmuff (1998) found that flow quality improvements to reduce Klebanoff streaks shifted the natural transition upstream, similar to Arnal \& Juillen (1978), who increased the FST and found a downstream transition shift on a body of revolution. However, Kendall (1991) observed increased TS-wave-packet growth rates in the presence of Klebanoff streaks.

Computations (Cossu \& Brandt 2002) and stability theory (Cossu \& Brandt 2004; Bagheri \& Hanifi 2007) have shown that the steady optimal streak (Andersson, Berggren \& Henningson 1999; Luchini 2000) reduces TS-wave growth rates. Streaks forced by roughness elements (Fransson et al. 2005a; Gürün 2006) or miniature vortex generators (Fransson \& Talamelli 2012) have also shown reduced TS-wave growth, and sometimes transition delay (Fransson et al. 2006; Shahinfar et al. 2012; Shahinfar, Sattarzadeh \& Fransson 2014). However, both steady and unsteady streaks forced by a single Squire mode have been found to increase TS-wave growth (Vaughan \& Zaki 2011), depending on streak amplitude, indicating that the forcing of the streak is an important consideration. Free-stream disturbances generated by wind-tunnel screens are known to force Klebanoff streaks, but the link is still tenuous. Klebanoff streak amplitude and the influence on transition have yet to be linked directly with measures of a screen.

Turbulent boundary layers are also affected by spanwise variation. Unexplained spanwise variation in both the tripped and non-tripped turbulent layers, generating a mixing flow, have been observed by Bell \& Mehta (1990). Dengel \& Fernholz (1989) found spanwise variation in the turbulent layer and showed direct linkage to the settling chamber screens by rotating them. Spanwise variation was considerably reduced by replacing the screen with one constructed from perforated metal.

\subsection{Spanwise variation empirically linked to settling chamber screens}

Wind-tunnel settling chamber screens and honeycombs are used to reduce FST levels and improve flow quality, yet many experimentalists identify them as directly influencing the test-section boundary layer. Bradshaw (1965) studied a tripped, turbulent boundary layer on the test-section floor that exhibited spanwise variation of skin friction in excess of $10 \%$. The spanwise variation was dependent on the individual screen, its orientation and was repeatable when the open-area ratio was greater than $57 \%$. Decreasing the open-area ratio below $57 \%$ produced a boundary layer with considerably increased spanwise variation. This was attributed to a spatial flow instability downstream of the screen called the coalescence of jets. 
The coalescence of jets is a local change of flow pattern that occurs downstream of low open-area ratio zithers. Requiring screens to have an open-area ratio greater than $57 \%$ has become a guideline when selecting screens for wind tunnels.

Crow (1966), in response to the findings of Bradshaw (1965), analytically investigated the effect of small, steady spanwise variations of transverse velocity above a laminar boundary layer. Small velocity variations could create spanwise variations in the boundary layer. Experiments by de Bray (1967) confirmed the findings of Bradshaw (1965). A high quality honeycomb was also observed to produce a more spanwise uniform boundary layer while locating the test-section plate on the wind-tunnel centreline could reduce the spanwise variation by $50 \%$ compared to the wind-tunnel wall boundary layer. de Bray (1967) concluded that immeasurable non-uniformities introduced by screens persist into the test section and affect the spanwise variation of the layer. He postulated that vortices of opposite rotation (apparently streamwise oriented) originate from adjacent openings in the screen and bundle together (coalesce) downstream.

Similarly, Patel (1964) observed reduced spanwise variation when using a honeycomb downstream of the settling chamber screens, although this configuration can increase FST levels (Mehta \& Bradshaw 1979). However, Scheiman \& Brooks (1981) found that a honeycomb upstream of a screen produced a greater reduction of turbulence levels. Patel (1964) also noted increased spanwise variation with dust accumulation on the screens, underscoring the sensitivity of the test-section layer to screen quality.

The widespread consensus is that jets coalesce downstream of the screen due to some 'instability' formed at low open-area ratios. From this instability, streamwise vortices form (de Bray 1967; Mehta \& Bradshaw 1979), which persist through the contraction and into the test-section layer. However, Mehta \& Hoffmann (1987) found increased spanwise variation does not always correlate directly with an open-area ratio of $57 \%$. Two screens, both with an open-area ratio of $58.8 \%$, created spanwise skin-friction variation of $10 \%$ and $18 \%$. They concluded the $57 \%$ open-area ratio criteria is not sufficient to guarantee two-dimensionality of the test-section boundary layer. Mehta (1985) also tested screens of varying materials and construction methods. Plastic screens were found to produce less spanwise variation relative to woven metal screens.

Increased spanwise variation of the test-section boundary layer can also be associated with increased FST levels. Klebanoff (1971) elevated the FST level in a wind tunnel with grids constructed of rope that were placed upstream of the contraction. A low-frequency spanwise thickening and thinning of the layer was observed that grew with increasing FST levels (Klebanoff streaks). However, the measurements of Watmuff (1998) suggest the link between FST and Klebanoff streaks is not simple. Watmuff found that replacing and tensioning the settling chamber screens reduced the FST level from $0.12-0.08 \%$, but the Klebanoff streaks in the boundary layer (measured by $u_{r m s}$ ) decreased by a factor of three. The unsteadiness in the layer was not spanwise uniform but clustered into 'clump' regions that did not shift with time. The unsteadiness in the layer was reduced by a further factor of two by reordering the screens based on quality, as measured from laser scans, from least uniform (worst quality) to most uniform (best quality) downstream.

Westin et al. (1994) compiled published results of Klebanoff streak growth and found considerable differences, even when scaled with the FST level. However, the observed spacing of Klebanoff streaks generally shows a more reasonable agreement, approximately twice the boundary-layer thickness $\left(\sim 2 \delta_{99}\right)$. Matsubara \& Alfredsson 
(2001) observed the physical spacing of Klebanoff streaks to be independent of the mesh spacing used in the construction of a grid placed in the test section to elevate the FST levels, however streak spacing has been found to be dependent on the free-stream environment (Fransson \& Alfredsson 2003; Ovchinnikov, Choudhari \& Piomelli 2008).

Swearingen \& Blackwelder (1986) found the 'natural' spacing of Görtler vortices to be sensitive to the settling chamber screens. The spacing was independent of the screen mesh length, test section width, distance of the last screen from the contraction and FST variation created by the removal of the honeycomb upstream of the screens. However, the spanwise pattern of Görtler vortices was stationary in time and strongly dependent on the downstream screen. Vertical cylinders oriented normal to the test-section leading edge, and placed in the tunnel contraction, were used to alter the screen wake. Cylinder spacing larger than the natural Görtler spacing did not substantially alter the spanwise pattern, but the cylinder wakes were clearly visible in the boundary layer as narrow regions superimposed on the 'natural' pattern. Reducing cylinder spacing created a near-periodic variation, approximating the cylinder spacing. The mechanism for the cylinder wake affecting the Görtler spacing was described as the creation of streamwise vorticity when the wakes intersect the leading edge and are stretched by the boundary layer. At elevated FST levels, travelling Görtler vortices can be important (Schrader, Brandt \& Zaki 2011; Wu, Zhao \& Luo 2011).

Unlike streaks and Görtler vortices, the growth of cross-flow vortices on swept wings does not appear to be sensitive to free-stream non-uniformity. Deyhle \& Bippes (1996) found no effect on cross-flow spacing when shifting screens to change the dominant free-stream wavelength. The cross-flow pattern shifted with movement of the body, indicating surface roughness was the dominant factor. However, cross-flow growth and transition is very sensitive to FST, and hence screens (see Hunt 2011).

All of these observations clearly link settling chamber screens with spanwise variation in the test-section boundary layer and establish screen open-area ratio and quality as causal factors without any satisfactory explanation. Stationary Klebanoff streaks and Görtler vortices, and differing spanwise skin friction measurements depending on test-section plate location, question any assumption of a homogeneous screen wake and FST across a wind-tunnel cross section.

\subsection{Flow downstream of screens}

The classical analysis of Taylor \& Batchelor (1949) considered the linear, inviscid flow of streamlines through a gauze (screen) where a pressure drop takes place. Classical analysis does not consider the details of the screen or honeycomb beyond the pressure drop and deflection coefficients (Laws \& Livesey 1978). However, Scheiman \& Brooks (1981) found screens suppressed longitudinal turbulence better than the lateral component, while honeycombs did the opposite. They deduced the mechanism responsible is different, which cautions the use of simple theory to understand the effects of screens, honeycomb or other turbulence manipulators.

Classical analysis predicts a pressure drop coefficient of 2.76 will remove any mean streamwise flow non-uniformity. Decreasing screen open-area ratio will increase the pressure drop. Hancock (1998) extended the analysis to multiple screens and found no series of screens can perfectly attenuate free-stream non-uniformity, although any series of screens can give significant attenuation if the sum of the pressure drops coefficients is greater than 2.5. Bradshaw (1965) recommended screens should have a pressure drop coefficient less than 1.6 to avoid jet coalescence. This is significantly lower than the analysis of Taylor \& Batchelor (1949) indicates is required to achieve 
uniform flow. Schubauer, Spangenberg \& Klebanoff (1950) and Bradshaw (1965) have recommended a series of lower pressure drop screens be used to achieve a high pressure drop.

Morgan (1960) summarises early work on the coalescence of jets behind screens and zithers of low open-area ratio. Important points are that the instability occurs for open-area ratios less than approximately $50 \%$, and that imperfections of the screen (quality) have been postulated as a possible cause. Earlier experimental work by Bohl (1940) (the original work is in German and the current authors cannot directly review it. The review is based on the reading of Morgan (1960) and Corrsin (1944)) studied the flow downstream of a zither constructed of sharp wooden slats and provided the first analytical treatment of the coalescence of jets. Stable flow (no coalescence of jets) was observed for an open-area ratio of $63 \%$ and unstable flow (with coalescence of jets) for an open-area ratio of $50 \%$. An analytical analysis was provided but Corrsin (1944) has criticised it for unclear physical assumptions in the derivation, although the results show qualitative agreement with experiment. Observations of the coalescence of jets have shown the flow pattern can be either stable in time or variable, and that multiple jets can coalesce at very low open-area ratios (Cheng \& Moretti 1988; Le Gal et al. 1996).

Böttcher \& Wedemeyer (1989) examined the steady wakes of screens and zithers as the sum of each individual wire's wake, governed by the linear diffusion equation. It should be noted that the coalescence of jets is equivalent to the merging of wakes (Corrsin 1944). The wake strength and wavelength of a zither was derived by considering each wire randomly perturbed from its position in a zither with perfect wire spacing. Direct comparison between theory and experiment was not possible as inputs to the wake strength formula had to be estimated. Their analysis offers the potential to relate screen quality to the downstream wake.

The wake turbulence of a screen is also affected by the open-area ratio and the coalescence of jets. Loehrke \& Nagib (1972) and Tan-Atichat, Nagib \& Loehrke (1982) found the decay of turbulent energy downstream of a low open-area ratio (30\%) perforated plate was greatly reduced relative to plates with open-area ratios of $51 \%$ and $58 \%$. They suggest the coalescence of jets may be responsible. Irregularities were also observed in the mean flow far downstream. Previously, Schubauer et al. (1950) had noted that low open-area ratio screens (high pressure drops) could produce abnormally large streamwise velocity fluctuations and less uniform mean flow, but the cause was not identified. Recent computations by Ertunç et al. (2010) show turbulence downstream of a symmetric (perfect) screen is not homogeneous. If the screen has small non-uniformities in its construction (variation in wire position), then the mean flow is also non-homogeneous.

No satisfactory explanation exists for the coalescence of jets, nor does the traditional inviscid analysis of screens predict its appearance or effects. To the authors knowledge, there has been no direct observation of the coalescence of jets for a screen (as opposed to a zither) and all reports of increased spanwise variation attributed to this phenomena have not directly observed its occurrence. How the change in flow pattern at a screen, located upstream of a contraction which produces near uniform streamwise velocity mean-flow but increases spanwise variation of the test-section boundary layer, is not fully explained.

\subsection{Creating the link to settling chamber screens}

Explaining the creation of spanwise variation and streaks in the boundary layer requires understanding of how disturbances grow in the layer, the receptivity of 
disturbances, the evolution of the disturbance in the free stream from their source and the creation of the disturbances at a source (screen). Recent work has focused on streak growth via non-modal theories (Andersson et al. 1999; Luchini 2000; Schmid 2007) or transient/algebraic growth (Ellingsen \& Palm 1975; Hultgren \& Gustavsson 1981; Butler \& Farrell 1992; Reddy, Schmid \& Henningson 2008). Asymptotic analyses have linked Klebanoff streaks to FST (Leib, Wundrow \& Goldstein 1999; Wundrow \& Goldstein 2001; Ricco 2009; Ricco, Luo \& Wu 2011) and highlighted the importance of free-stream anisotropy. Goldstein, Leib \& Cowley (1992) and Goldstein \& Leib (1993) describe the receptivity of normal and streamwise vorticity that creates streaks, while the computations of Schrader et al. (2010) and Pook \& Watmuff (2014) demonstrate the preference for the receptivity of streamwise vorticity.

Pook \& Watmuff (2014) have also demonstrated how normal vorticity entering a wind-tunnel contraction can be tilted and stretched into significant streamwise vorticity at the exit, away from the wind-tunnel centreline. This is consistent with the observations by de Bray (1967) of increased skin friction variation away from the wind-tunnel centreline, suggesting the tilting and stretching of normal vorticity in the contraction can be a significant mechanism in the generation of spanwise variation of the test-section boundary layer and Klebanoff streaks. Any analysis that attempts to link spanwise variation to settling chamber screens must consider the contraction. Streaks that link directly to a physical, free-stream disturbance from a defined source in a wind tunnel may be important for determining their effect on the boundary-layer stability and transition.

\subsection{Overview}

This paper will focus on streak generation in a 'clean' wind-tunnel facility where the boundary-layer spanwise variation is time invariant, e.g. Watmuff (1998) with FST $\sim 0.1 \%$. The streaks, created by an imperfect zither located upstream of a contraction, will be weak and bypass transition would not be expected. Modelling a zither is less computationally expensive than a screen, and provides an initial step towards Morkovin's call to link screens with the test-section boundary layer. The current work is strictly applicable to zithers with steady laminar wakes, however qualitative similarities with observations made from screens will be noted. The work is divided into the following sections:

(i) Section 2 examines the steady laminar wakes of an imperfect zither, extending the analysis of Böttcher \& Wedemeyer (1989). Substantial variation of drag across a zither is shown to lead to a reduced wake decay rate, but this decay rate is not so easily realised.

(ii) Section 3 passes the wakes through a 5:1, two-dimensional contraction. This will create streamwise vorticity at the exit via tilting and stretching of normal vorticity.

(iii) Section 4 documents the streaks formed in the flat-plate boundary layer by the wake of streamwise vorticity.

(iv) Section 5 assesses the linear stability of the test-section streak base-flows.

The contraction geometry, and the test-section leading edge shape and position, are the same as Watmuff (2006), Pook (2013), Pook \& Watmuff (2014). An overview is provided in figure 1 . 
Diffusion decreases wake strength. Small wavelengths decay more rapidly, leaving

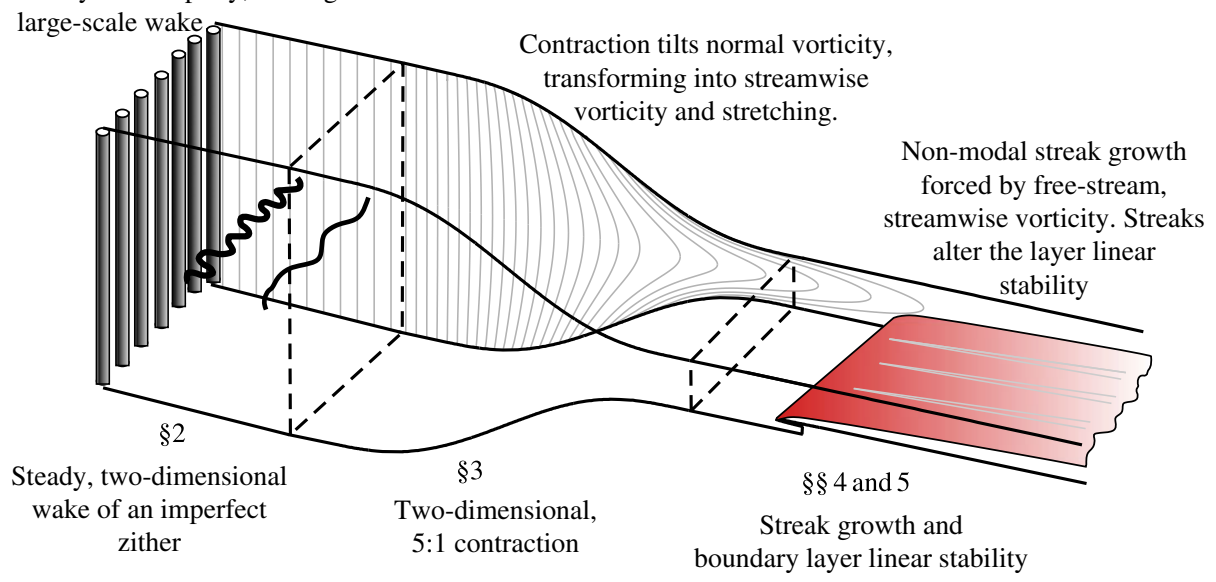

FIGURE 1. (Colour online) Overview of geometry and section breakdown.

\section{The steady laminar wake of a zither}

The (simplified) governing equation of a far wake is the linear diffusion equation (Böttcher \& Wedemeyer 1989; Batchelor 2000),

$$
U u_{x}=v u_{z z}
$$

where $u=u(x, z)$ is the streamwise velocity of the wake, $U$ the uniform free-stream flow and $v$ is the fluid kinematic viscosity. Considering a spanwise $(z)$ periodic domain of width $L$ and a zither with $N$ wires, it can be shown that the solution to (2.1) is,

$$
u(x, z)=\sum_{k=-\infty}^{\infty} a_{k} \exp \left(\frac{2 \pi \mathrm{i} k z}{L}\right) \exp \left(-4 \pi^{2} K^{2} \bar{x}\right)
$$

where $a_{k}$ are the unknown Fourier coefficients at the wake origin, $k$ is the integer wavenumber, $K$ is $k / N$ and $\bar{x}$ is a non-dimensional streamwise distance defined by,

$$
\bar{x}=\frac{x}{M} \frac{1}{R e_{M}},
$$

where $R e_{M}$ is the Reynolds number based on perfect zither wire spacing $(M)$. The wake energy is found as,

$$
\overline{u^{2}}=\frac{1}{L} \int_{0}^{L}(U-u)^{2} \mathrm{~d} z=\sum_{k=-\infty}^{\infty}\left|a_{k}\right|^{2} \exp \left(-8 \pi^{2} K^{2} \bar{x}\right)
$$

where the mean flow mode $(k=0)$ is not included in the summation. The value of a given Fourier coefficient in the downstream wake can be evaluated by multiplying it with,

$$
f=\exp \left(-4 \pi^{2} K^{2} \bar{x}\right) .
$$




\subsection{Summation of wakes}

The wake of a zither will be considered as the summation of each individual wire's wake. Unlike Böttcher \& Wedemeyer (1989), each wire will be assumed to have an individual wake. Each wake is given by an unknown function, $W_{n}\left(z-z_{n}\right)$, where $z_{n}$ is the spanwise location of the $n$th wire. Far downstream, the wavelengths are large in comparison to the wire spacing, as observed by Böttcher \& Wedemeyer (1989). They argue that the wake function of a wire can be considered as a point source,

$$
\int W_{n}\left(z-z_{n}\right)=q_{n} \delta\left(z-z_{n}\right),
$$

where $\delta\left(z-z_{n}\right)$ is the Dirac function and $q_{n}$ is the source strength of the $n$th wire. Assuming only a drag force acting on the wire (no lateral force component), $q_{n}$ is then related to the drag force $\left(D_{n}\right)$ by $D_{n}=\rho U q_{n}$, where $\rho$ is density (Batchelor 2000). Every wire in the zither is perturbed from its perfect position $(M n)$, giving the position and source strength of the $n$th wire as,

$$
z_{n}=M\left(n+\delta_{n}\right), \quad q_{n}=\bar{q}\left(1+\epsilon_{n}\right),
$$

where $\delta_{n}$ and $\epsilon_{n}$ are non-dimensional random variables with zero means and $\delta_{n} \ll M$, $\epsilon_{n} \ll 1$ and $\bar{q}$ is the mean source strength. The Fourier coefficients of (2.2) are then,

$$
a_{k}=\frac{\bar{q}}{N M} \sum_{n=1}^{N}\left(2 \pi \mathrm{i} K \delta_{n}+\epsilon_{n}-2 \pi \mathrm{i} K \epsilon_{n} \delta_{n}\right) \exp (-2 \pi \mathrm{i} K n),
$$

where the first exponential term of (2.2) has been expanded with a power series $\left(e^{x} \approx\right.$ $1+x)$.

\subsection{Predicted wake from a zither with imperfect wire spacing and source strength}

Assuming all wavelengths are excited relatively equally by the distributions of $\delta_{n}$ and $\epsilon_{n}$ gives the wake energy as,

$$
\overline{u^{2}}=\frac{\bar{q}^{2}}{N^{2} M^{2}} \sum_{k=-\infty}^{\infty}\left(4 \pi^{2} K^{2} N \sigma_{\delta}^{2}+N \sigma_{\epsilon}^{2}\right) \exp \left(-8 \pi^{2} K^{2} \bar{x}\right),
$$

where,

$$
\sigma_{\delta}^{2}=\frac{1}{N} \sum_{n=1}^{N} \delta_{n}^{2}, \quad \sigma_{\epsilon}^{2}=\frac{1}{N} \sum_{n=1}^{N} \epsilon_{n}^{2},
$$

and terms with higher products of $\delta_{n}$ and $\epsilon_{n}$ are assumed negligible. Considering an infinite zither $(N \rightarrow \infty, k / N \rightarrow K)$ allows the summation to be replaced with the integral,

$$
\overline{u^{2}}=\frac{\bar{q}^{2}}{M^{2}} \int_{-\infty}^{\infty}\left(4 \pi^{2} K^{2} \sigma_{\delta}^{2}+\sigma_{\epsilon}\right) \exp \left(-8 \pi^{2} K^{2} \bar{x}\right) \mathrm{d} K .
$$

The wavenumber with peak energy can be found from the integrand as,

$$
K=\frac{1}{2 \sqrt{2} \pi \bar{x}} \sqrt{\bar{x}-2 \frac{\sigma_{\epsilon}^{2}}{\sigma_{\delta}^{2}} \bar{x}^{2}},
$$


giving the dominant wake wavelength as,

$$
\frac{\lambda}{M}=\frac{2 \sqrt{2} \pi \bar{x}}{\sqrt{\bar{x}-2 \frac{\sigma_{\epsilon}^{2}}{\sigma_{\delta}^{2}} \bar{x}^{2}}} .
$$

For small $\bar{x}$, or when $\sigma_{\epsilon}$ is small, the wavelength will be independent of the zither geometry,

$$
\frac{\lambda}{M}=\sqrt{8 \pi^{2} \bar{x}},
$$

as originally derived by Böttcher \& Wedemeyer (1989).

The mean energy of the wake is found as the solution of (2.11). The average wake strength is non-dimensionalised by $U$, giving the combined wake strength equation as,

$$
\Delta u=\frac{0.2233 \bar{q} \sigma_{\delta}}{M U \bar{x}^{0.75}} \sqrt{1+4 \frac{\sigma_{\epsilon}^{2}}{\sigma_{\delta}^{2}} \bar{x}} .
$$

where $\Delta u$ is defined as $\Delta u=\sqrt{\overline{u^{2}}} / U$.

\subsection{Predicted zither wake from only imperfect wire positions}

Assuming each wire is identical, and neglecting the change in wire source strength due to an error in position, then the Fourier coefficients of (2.8) are given by,

$$
a_{k}=\frac{\bar{q}}{N M} \sum_{n=1}^{N}-2 \pi \mathrm{i} K \delta_{n} \exp (-2 \pi \mathrm{i} K n) .
$$

The dominant wavelength of the zither wake is found as (2.14) and the average wake strength of a zither with only imperfect wire position is,

$$
\Delta u=0.2233 \frac{\bar{q} \sigma_{\delta}}{M U \bar{x}^{0.75}},
$$

as originally derived by Böttcher \& Wedemeyer (1989).

\subsection{Predicted zither wake from only imperfect wire source strengths}

Assuming only imperfection of wire source strength gives the Fourier coefficients,

$$
a_{k}=\frac{\bar{q}}{N M} \sum_{n=1}^{N} \epsilon_{n} \exp (-2 \pi \mathrm{i} K n) .
$$

The dominant wavenumber is found as $k=0$, but as the wake has no zero mode, $k=1$ will dominate far downstream. The average wake strength for a zither with imperfect wire source strength is found as,

$$
\Delta u=0.4466 \frac{\bar{q} \sigma_{\epsilon}}{M U \bar{x}^{0.25}} .
$$



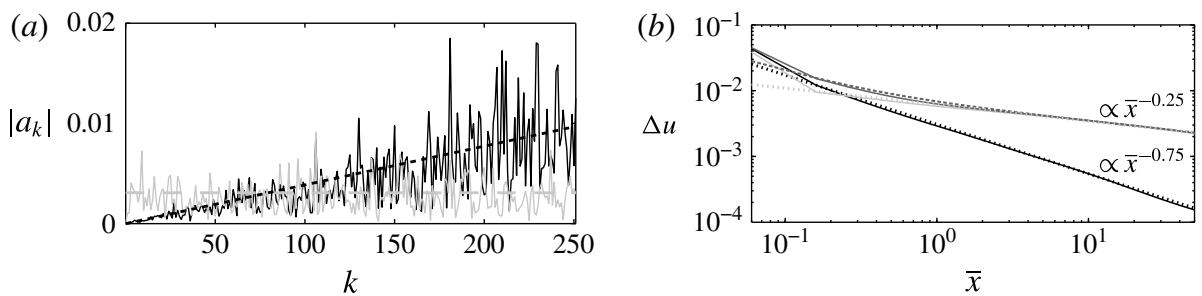

FIgURE 2. (a) Fourier coefficients at the zither due to: grey solid line, random normal distribution of wire drag; grey dashed, mean distribution of drag, (2.21); black solid, random normal distribution of wire position; black dashed, mean distribution of position, (2.20). (b) Example wake decay: light grey solid, random normal distribution of wire drag calculated with (2.18) and (2.4); light grey dashed, variation of drag, (2.19); black solid, random normal distribution of wire position calculated with (2.16) and (2.4); black dashed, variation of position, (2.17); dark grey solid, random normal distribution of wire drag and position calculated with (2.8) and (2.4); dark grey dashed, variation of drag and position, the combined wake strength equation, (2.15).

\subsection{Differing zither wake decay rates}

The wake strength formulas (2.15), (2.17) and (2.19) are compared in figure 2 for zithers with: imperfect wire spacing and source strength $\left(\sigma_{\delta}=\sigma_{\epsilon}=0.05\right)$; only imperfect wire position $\left(\sigma_{\delta}=0.05, \sigma_{\epsilon}=0\right)$; and only imperfect source strength $\left(\sigma_{\delta}=0, \sigma_{\epsilon}=0.05\right)$. The wake decay of the imperfect wire position zither differs significantly to a zither with only imperfect source strength, predominately due to the respective $\bar{x}^{-0.75}$ and $\bar{x}^{-0.25}$ dependencies. For the same standard deviation of imperfection, the zither with only source strength variation will be weaker close to the zither, but stronger far downstream. The wake decay is explained by the Fourier coefficient distributions shown in figure 2. The distribution for a zither with only variation in wire position is approximated by,

$$
a_{k P}=\frac{2 \pi k \sigma_{\delta} \bar{q}}{M \sqrt{N}} .
$$

The distribution for variation only in source strength is approximated as,

$$
a_{k D}=\frac{\sigma_{\epsilon} \bar{q}}{M \sqrt{N}}
$$

Variation in wire source strength can create significantly stronger small wavenumbers (large wavelengths), that decay slower and create a stronger far wake. This leads to a hypothesis that significant spanwise variation in the test-section boundary layer is linked to screens that have significant spatial variation of source strength. This spatial variation may be induced by poor quality screens that have larger variations in wire position which, particularly for lower open-area ratios, may lead to nearby wires influencing each other's source strength (drag) and creating a stronger far wake.

\subsection{Zither CFD domain and methods}

Navier-Stokes simulations (CFD) will be used to study ten zithers with differing combinations of open-area ratio and random wire position error. The steady, 
(a)

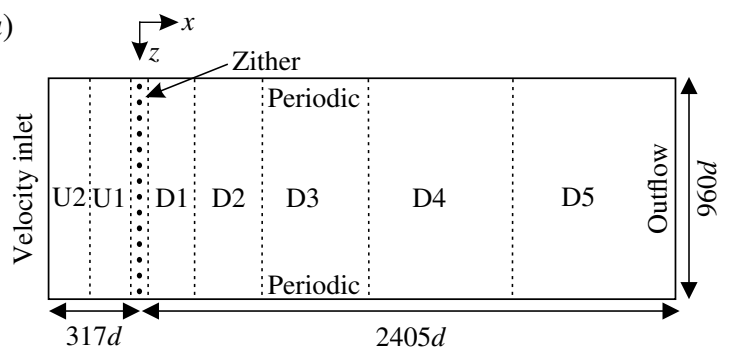

(b)

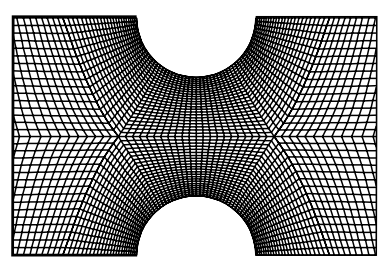

Figure 3. (a) Overview of the zither mesh domain. Marked regions start at streamwise positions: $\mathrm{U} 2$ at $-317 d$, $\mathrm{U} 1$ at $-76 d$, Zither at $-7 d$ to $7 d, \mathrm{D} 1$ at $7 d, \mathrm{D} 2$ at $67 d$, D3 at 205d, D4 at 405d, D5 at 805d. (b) Close-up of the CFD mesh between two zither wires. Every second line shown.

pressure-based solver (second-order upwind differencing for pressure, third-order MUSCL differencing for momentum) of the ANSYS Fluent CFD package is used. Solution convergence is judged by the constancy of the far wake with increasing iteration and convergence of global residual monitors. An overview of the zither domain and mesh is shown in figure $3(a)$. The velocity inlet-boundary-condition is 317 diameters $(d)(80.47 \mathrm{~mm})$ upstream of the zither while the outflow boundary condition is located at $2405 d(610.8 \mathrm{~mm})$. Periodic boundary conditions are used in the spanwise direction.

To reduce the total mesh control volumes (CV), eight regions with varying resolution are used as the wake spanwise scale increases. Each region is composed of structured quadrilateral $\mathrm{CV}$ aligned with the uniform flow direction. Hanging nodes are used to halve the number $\mathrm{CV}$ in the spanwise direction at each region boundary. Figure 3(b) shows the mesh between wires. There are $216 \mathrm{CV}$ on the surface of a wire. Total mesh size varies between 23.4 and 44.2 million $\mathrm{CV}$, depending on the open-area ratio. Refining the entire $\beta=60 \%$ with $\sigma_{\delta}=0.05$ mesh by a factor 2 in each direction altered wire forces by less than $0.5 \%$ and has a negligible effect on the far wake (see figure $4 c$ ).

The spanwise domain is the same for all zithers $(L=243.84 \mathrm{~mm})$, with up to 576 wires depending on the open-area ratio (see table 1). Numerical tests comparing (2.2) with (2.15) show this is enough wires for the averaging in (2.15) to be representative beyond $\bar{x}=30$ (see Pook 2013). The spanwise domain is also more than six times wider than the wavelength for optimal, non-modal streak growth (Andersson et al. 1999) at the downstream end of the model test section used in $\S 4$.

\subsection{Zither geometry}

Table 1 lists the geometry parameters for all the zithers which are composed of circular wires arranged in a line perpendicular to the free stream. All wires have a diameter of $254 \mu \mathrm{m}$, the same size used by Pook \& Watmuff (2014). Four open-area ratios $(\beta)$ are used, $\beta=40 \%$ where coalescence of jets is expected, $50 \%, 60 \%$ and $66.67 \%$ where coalescence of jets is not expected. The open-area ratio, diameter and the mesh spacing of the perfect zither (uniformly spaced wires) are related by,

$$
\beta=1-\frac{d}{M}
$$



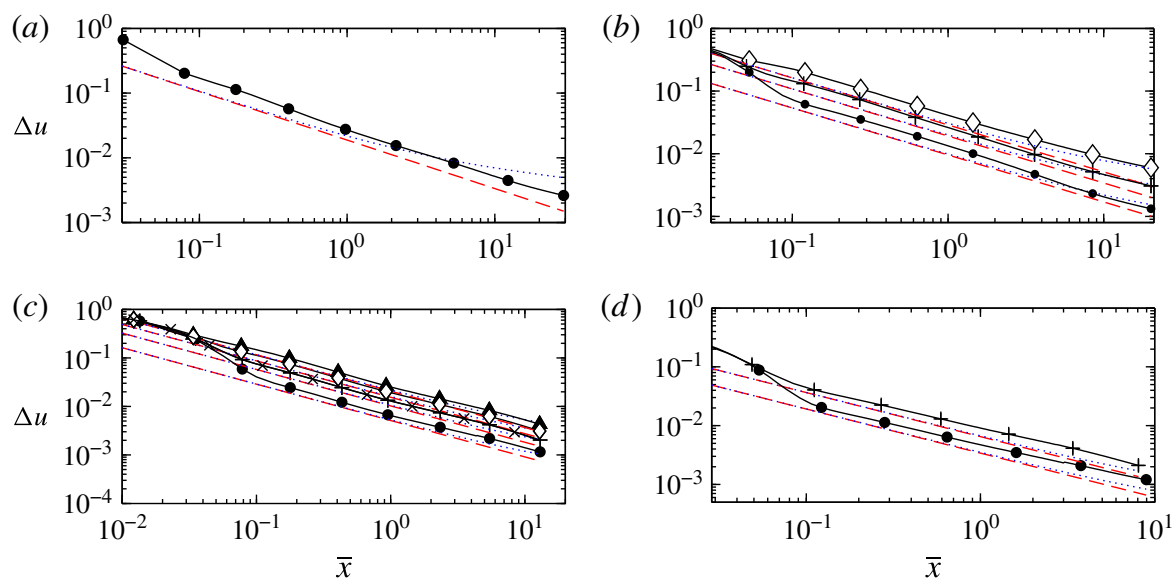

FIGURE 4. (Colour online) Zither wake strength from CFD simulations compared to prediction: (a) $\beta=40 \%$; (b) $\beta=50 \%$; (c) $\beta=60 \%$; (d) $\beta=66.67 \%$. Lines: - - prediction due to only position variation $(2.17) ; \cdots \ldots$ prediction of combined wake strength (2.15); $\rightarrow$ CFD wake for $\sigma_{\delta}=0.025 ; \rightarrow$ CFD wake for $\sigma_{\delta}=0.05 ; \rightarrow$ CFD wake for $\sigma_{\delta}=0.075 ; \_$CFD wake for $\sigma_{\delta}=0.1$. For $(b), \star \star$ refined mesh for $\sigma_{\delta}=0.05$.

Each wire $(n)$ is randomly perturbed from its position in the perfect zither by some distance. A normal distribution is used for the random variation of $\delta_{n}$, with (near) zero mean and a given standard deviation $\left(\sigma_{\delta}\right)$ listed in table 1 (see Pook 2013 for quantilequantile plots). The $\beta=60 \%$ zithers share the same distribution of $\delta_{n}$, i.e. the differing standard deviation is achieved by multiplying by a constant. The same applies for the $\beta=66.67 \%$ zithers. The $\beta=50 \%$ zithers all have differing distributions. A constant $\sigma_{\delta}$ implies a decreasing physical error in wire position with decreasing open-area ratio. The largest standard deviation in physical units for the zithers studied is $57.1 \mu \mathrm{m}$, or $22 \%$ of the wire diameter. The smallest is $10 \mu \mathrm{m}$, or $4 \%$ of the wire diameter. The uniform free stream is $U=1.7 \mathrm{~m} \mathrm{~s}^{-1}$ giving a Reynolds number based on wire diameter $R e_{d}=29.6$ for all zithers, except the $\beta=66.67 \%$ with $\sigma_{\delta}=0.05$ zither that uses $U=1.9 \mathrm{~m} \mathrm{~s}^{-1}$. The zithers are sub-critical (do not shed eddies).

Table 1 shows that the mean wire source strength is (near) invariant to the standard deviation of wire position variation. The wire source strength is obtained from the CFD wire force data and the mean calculated by,

$$
\bar{q}=\frac{1}{\rho U N} \sum_{n=1}^{N} D_{n} .
$$

The drag coefficient $\left(C_{d}\right)$ is defined as $D=0.5 \rho U^{2} d C_{d}$. The pressure drop coefficient $\left(P D=\Delta p /\left(0.5 \rho U^{2}\right)\right)$ is also listed.

\subsection{Wake strength}

Figure 4 compares the CFD wake strength with the predicted wake strength due only to variation in wire position (2.17), and the combined wake strength equation (2.15). Beyond $\bar{x} \gtrsim 0.1$, the CFD wakes decay as $\bar{x}^{-0.75}$. However, at $\bar{x}=1$, the CFD wake strengths are 20-40\% greater than predicted by (2.17) (see Pook 2013), with the error 


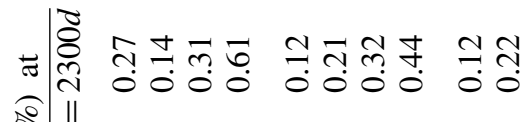

$\left.\underbrace{2}\right|_{x} ^{11}$

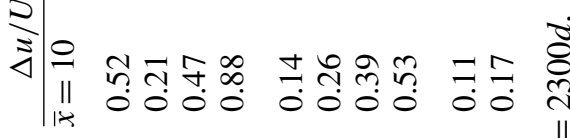

దำ

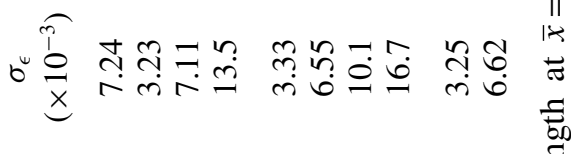

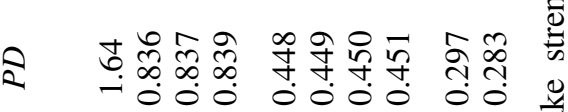

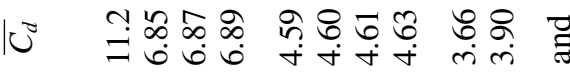

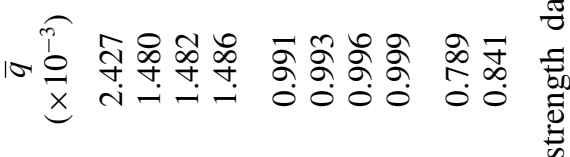

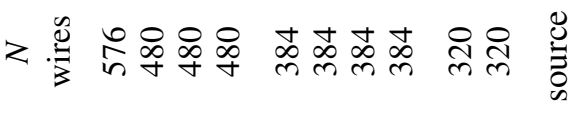

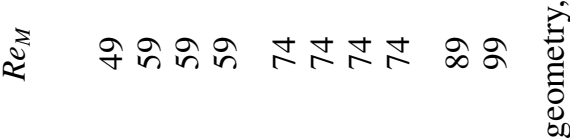

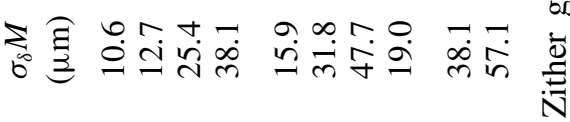

○

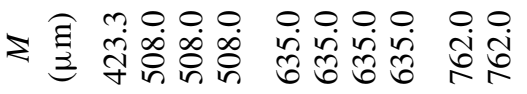

风 

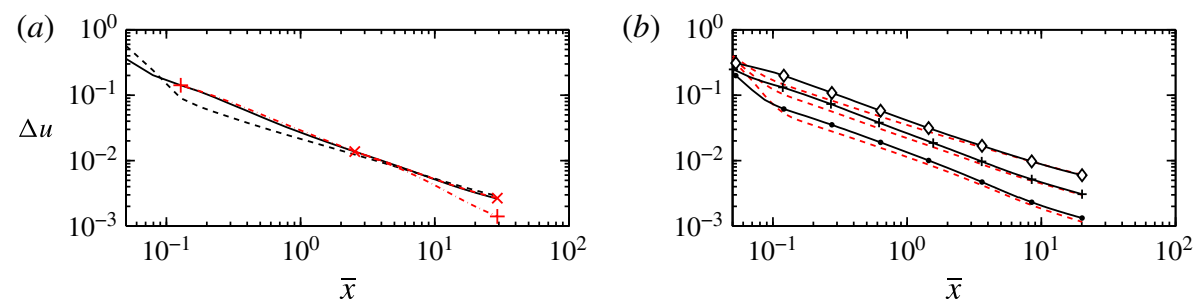

FIgURE 5. (Colour online) (a) The effect of a downstream initial condition for the $\beta=$ $40 \%, \sigma_{\delta}=0.025$ zither. — CFD; - - - calculated with (2.1) and (2.8); +.-.+ calculated with (2.1) from initial condition at $\bar{x}=0.13 ; \times-\cdots \times$ calculated with (2.1) from initial condition at $\bar{x}=2.5$. (b) $\beta=50 \%$ zithers CFD wake strength compared to calculation with (2.1) and (2.8). Lines and markers as for figure 2.
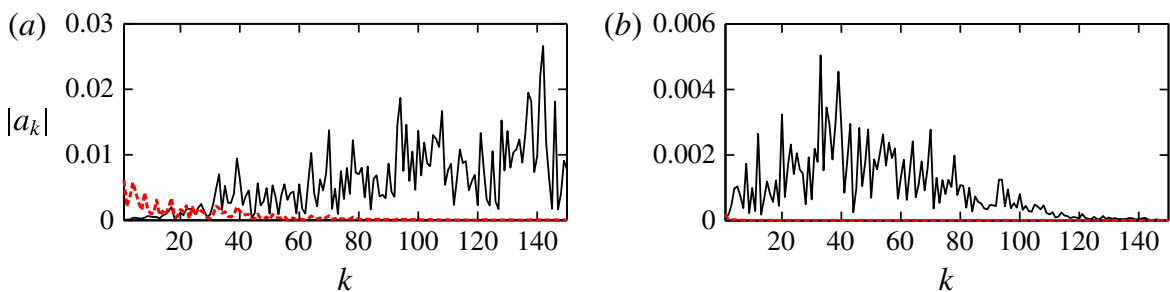

FIGURE 6. (Colour online) FFT of streamwise velocity and pressure for the $\beta=40 \%$, $\sigma_{\delta}=0.025$ zither: $(a) \bar{x}=0.13 ;(b) \bar{x}=2.5$. Lines: — streamwise velocity; - - - pressure.

increasing with the standard deviation of wire position variation $\left(\sigma_{\delta}\right)$ and decreasing open-area ratio. By $\bar{x}=10$, the CFD wake strengths are 20-70\% stronger, indicating a decay-rate slower than $\bar{x}^{-0.75}$ but not nearly as dramatic as predicted by (2.15).

Table 1 shows $\sigma_{\epsilon} / \sigma_{\delta}$ is a near constant 0.13 for the $\beta=60 \%$ and $\beta=66.67 \%$ zithers when $\sigma_{\delta} \leqslant 0.05$. The wake strength at a given streamwise distance for the $\beta=$ $60 \%$ and $66.67 \%$ zithers scales near linearly with $\sigma_{\delta}$. However, the $\beta=50 \%$ zithers show linear scaling only for $\sigma_{\delta}=0.025$ and 0.05 . The $\sigma_{\delta}=0.075$ zither wake strength is significantly greater than a linear scaling, indicating the wake strength due to only variation in wire position (2.17) does not predict the correct wake decay for zithers with large $\sigma_{\delta}$ which induces variations of drag across the zither. With decreasing openarea ratio, the ratio $\sigma_{\epsilon} / \sigma_{\delta}$ is seen to increase but only substantially for the $\beta=40 \%$ zither. However, its wake decay proportional to $\bar{x}^{-0.75}$ indicates a flawed assumption in the derivation of the combined wake strength equation (2.15).

\subsection{Validity of the linear diffusion equation}

The $\beta=40 \%$ zither CFD wake is sampled and used as a downstream initial condition to (2.1) as validation. Figure 5 shows using an initial condition sampled at $\bar{x}=2.5$ where $\Delta u=1 \%$, predicts a downstream wake in agreement with CFD. Using a fast Fourier transform (FFT) on the sampled wakes, figure 6, shows an initial condition too close to the zither fails as low-wavenumber variations of pressure have not been recovered into velocity. Fourier coefficients calculated at the zither with both wire drag and drag position are used to predict the wake in figure 5. The predicted wake undershoots the CFD results between $\bar{x}=0.1$ and $\bar{x}=6$, before showing reasonable 

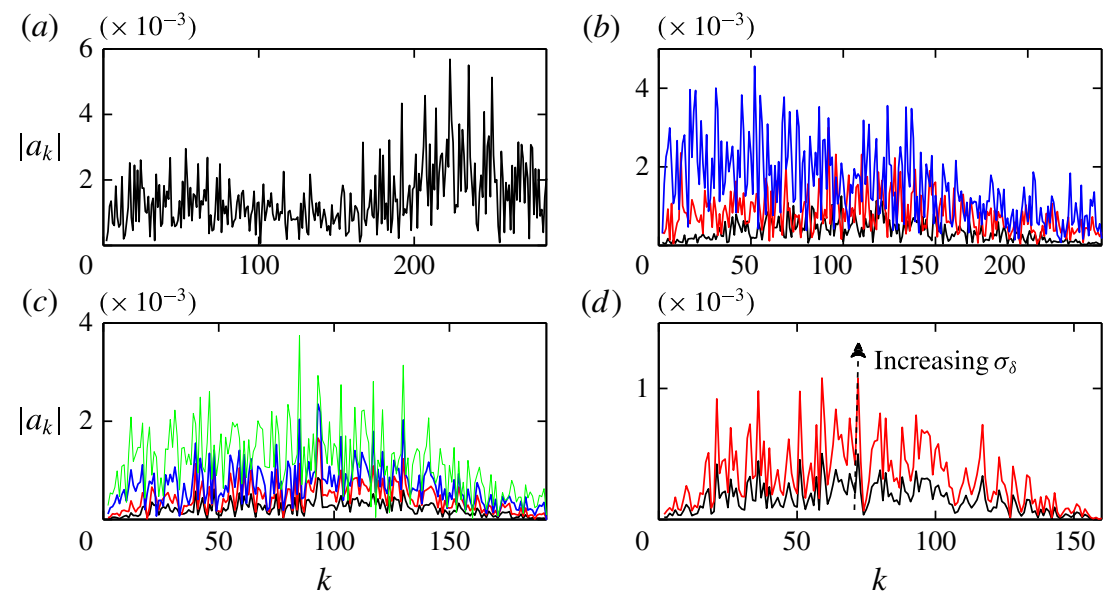

(d)

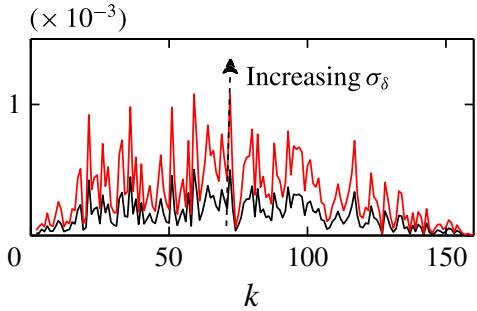

FIgURE 7. (Colour online) Fourier coefficients at the zither due to variation in drag only, calculated with (2.18): (a) $\beta=40 \%$; (b) $\beta=50 \%$; (c) $\beta=60 \%$; (d) $\beta=66.67 \%$. Increasing coefficients is increasing $\sigma_{\delta}$. Lines: black, $\sigma_{\delta}=0.025$; red, $\sigma_{\delta}=0.05$; blue, $\sigma_{\delta}=0.075$; green, $\sigma_{\delta}=0.1$.

agreement further downstream. As wire drag includes the effect of pressure, the linear diffusion equation can be used with known wire drag to predict the far wake.

The relative error between CFD wake strength and (2.1) using known wire drag is less than $10 \%$ for $\bar{x}>1$, for all zithers. Equation (2.17) under-predicts wake strength primarily because it neglects the variation in wire drag.

\subsection{Distribution of source strength (drag)}

Figure 7 shows the Fourier spectra due to only variation in wire drag, calculated with (2.18). The magnitude of the $\beta=60 \%$ and $66.67 \%$ zither Fourier coefficients increase from $k=0$, peak at approximately $k=100$, before diminishing. Approximating with the mean Fourier coefficient, as $a_{k D}$ does, will significantly over estimate the effect of wire drag variation for large wavelengths. The combined wake equation will over predict the wake strength at large $\bar{x}$. For $\beta=50 \%$, the Fourier coefficients for small $k$ increase with $\sigma_{\delta}$. Only for the $\sigma_{\delta}=0.75$ zither are the Fourier coefficients spread relatively evenly across the spectrum at low wavenumbers, meaning $\sigma_{\epsilon}$ should be an accurate representation. The wake decay should reduce from $\bar{x}^{-0.75}$ at large streamwise distances. Indeed, figure 4 does show the wake decay reducing for this zither.

The Fourier spectrum of the $\beta=40 \%$ zither is different to the other zithers, with the largest coefficients occurring at wavenumbers $k>200$, raising $\sigma_{\epsilon}$ but not affecting the far wake. A wavenumber of $k=288$ corresponds to a wavelength of $2 M$, i.e. a wavelength that could be expected to be associated with the coalescence of adjacent jets.

The over prediction of wake strength by the combined wake strength equation (2.15) is attributed to the assumed Fourier coefficient distribution due to variation in wire source strength (drag), $a_{k D}$. Approximating the Fourier coefficients due to wire force variation as constant (independent of $k$ ) is not valid and over predicts the wake strength for large $\bar{x}$. Equations to predict wake strength more accurately require an understanding of how the drag of a wire varies with an error in its position, particularly at low wavenumbers. 

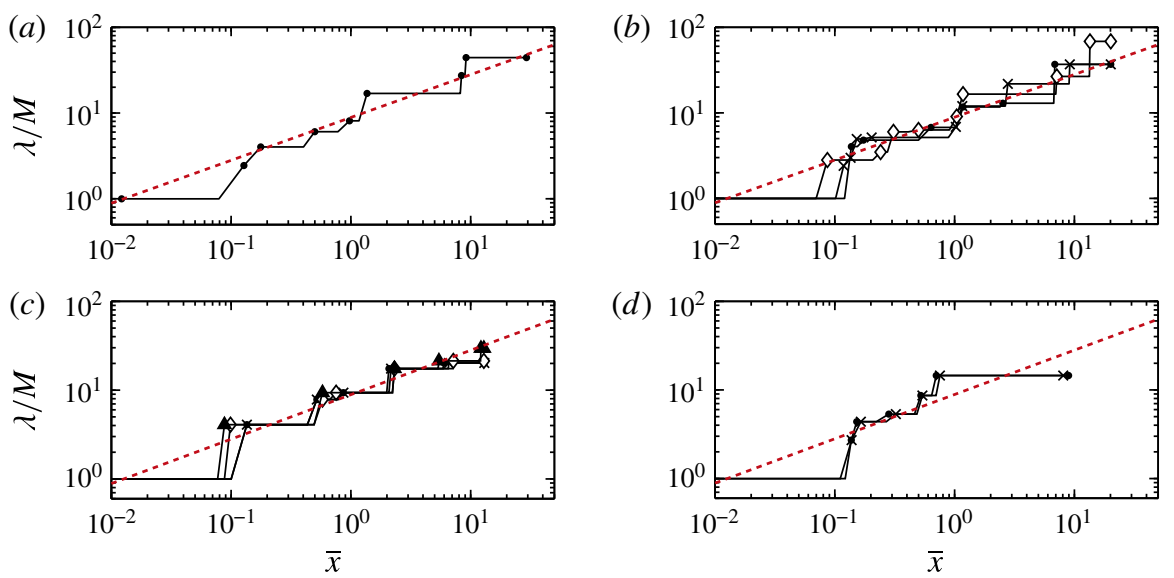

FIGURE 8. (Colour online) Wavelength of the peak Fourier mode in the CFD simulation; (a) $\beta=40 \%$; (b) $\beta=50 \%$; (c) $\beta=60 \%$; (d) $\beta=66.67 \%$. Lines: - - - wavelength predicted by (2.14); marked lines as for figure 4 .

\subsection{Wake wavelength}

The dominant wavelength at each streamwise position is extracted from the CFD wakes using an FFT of the streamwise velocity. Figure 8 shows the dominant wavelength increases with $\bar{x}^{0.5}$ and is independent of the zither geometry, as predicted by (2.14). Wake profiles can also be calculated from knowledge of the individual wire source strength and position data (see Pook 2013).

\subsection{Coalescence of jets}

Figures 9 and 10 show contours of streamwise velocity for a limited extent $(<10 \%)$ of the $\beta=40 \%, 50 \%$ and $60 \%$ zithers. The $\beta=60 \%$ zithers share the same wire perturbation pattern. Apart from the longer jets and wakes, the flow pattern does not significantly change over the $\sigma_{\delta}$ range investigated. There is minimal deflection of the jets that would be taken to indicate the coalescence of jets in experimental flow visualisation (see Bradshaw 1965; Le Gal et al. 1996), and table 1 shows $\sigma_{\epsilon} / \sigma_{\delta}$ is near constant. For the $\beta=50 \%$ with $\sigma_{\delta}=0.075$ zither shown in figure $10(c)$, the jets emanating near the cylinder at $z / d \approx 135$ are visibly deflected away from each other, creating an extended region of low-speed flow. More instances of visible jet deflection can be observed for this zither, and particularly the $\beta=40 \%$ zither, but not the other zithers. The ratio $\sigma_{\epsilon} / \sigma_{\delta}$ increases for zithers with instances of jet deflection.

The observed instances of jet deflection in figure 10 are similar to the experimental flow visualisations of Le Gal et al. (1996). However, Le Gal et al. (1996) observed significant jet deflection for the majority of jets. As previously mentioned, the Fourier coefficients of the $\beta=40 \%$ zither wire drag increase rapidly for $k>200$. This indicates a flow pattern that possibly correlates to the coalescence of jets. However, such small wavelengths have no effect on the far wake strength. For all other zithers, there is no trend towards increased drag variation at wavelengths approaching $2 M$ relative to large wavelength, although the Fourier coefficients for the $\beta=50 \%$ with $\sigma_{\delta}=0.075$ are appreciable at short wavelengths. The authors' opinion is that the coalescence of jet phenomena (large jet deflection visible in contours) appears for 

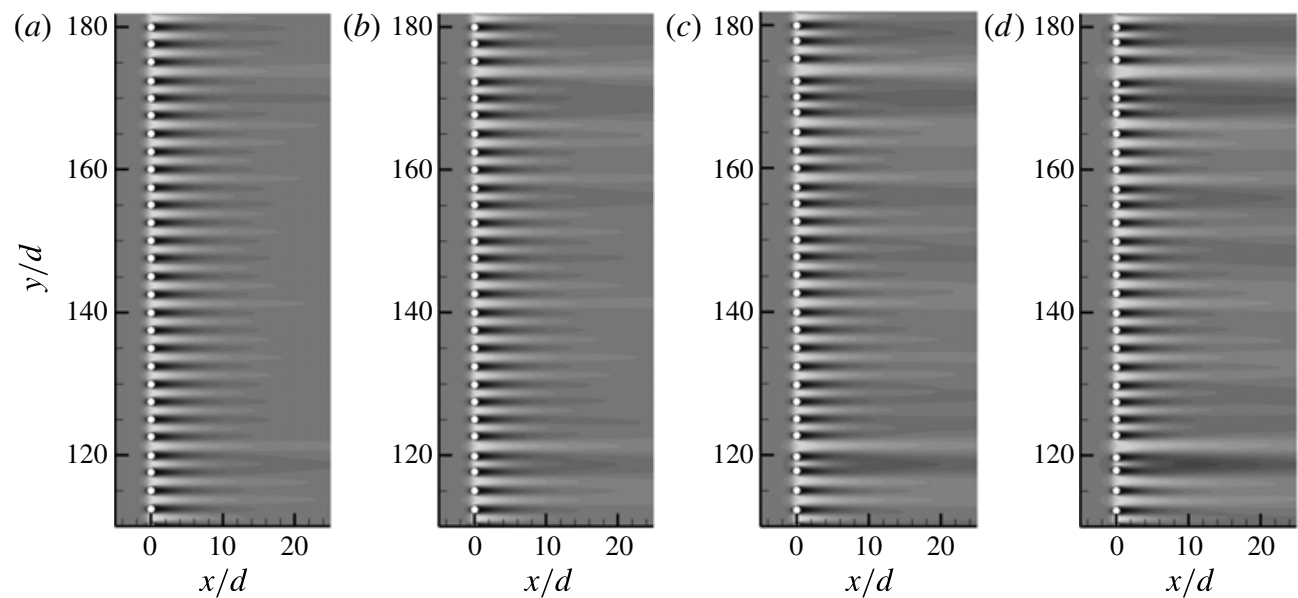

$(\Delta u)$

$$
\begin{array}{llllllllllllll}
-0.2 & 0 & 0.2 & 0.4 & 0.6 & 0.8 & 1.0 & 1.2 & 1.4 & 1.6 & 1.8 & 2.0 & 2.2 & 2.4
\end{array}
$$

FIGURE 9. Contours of streamwise velocity scaled by free-stream velocity $U$ (see insert for scale) for a limited extent $(<10 \%)$ of the zithers, $\beta=60 \%$ with: $(a) \sigma_{\delta}=0.025$, $\sigma_{\epsilon} / \sigma_{\delta}=0.13 ;(b) \sigma_{\delta}=0.05, \sigma_{\epsilon} / \sigma_{\delta}=0.13 ;(c) \sigma_{\delta}=0.075, \sigma_{\epsilon} / \sigma_{\delta}=0.13 ;$ (d) $\sigma_{\delta}=0.1$, $\sigma_{\epsilon} / \sigma_{\delta}=0.17$
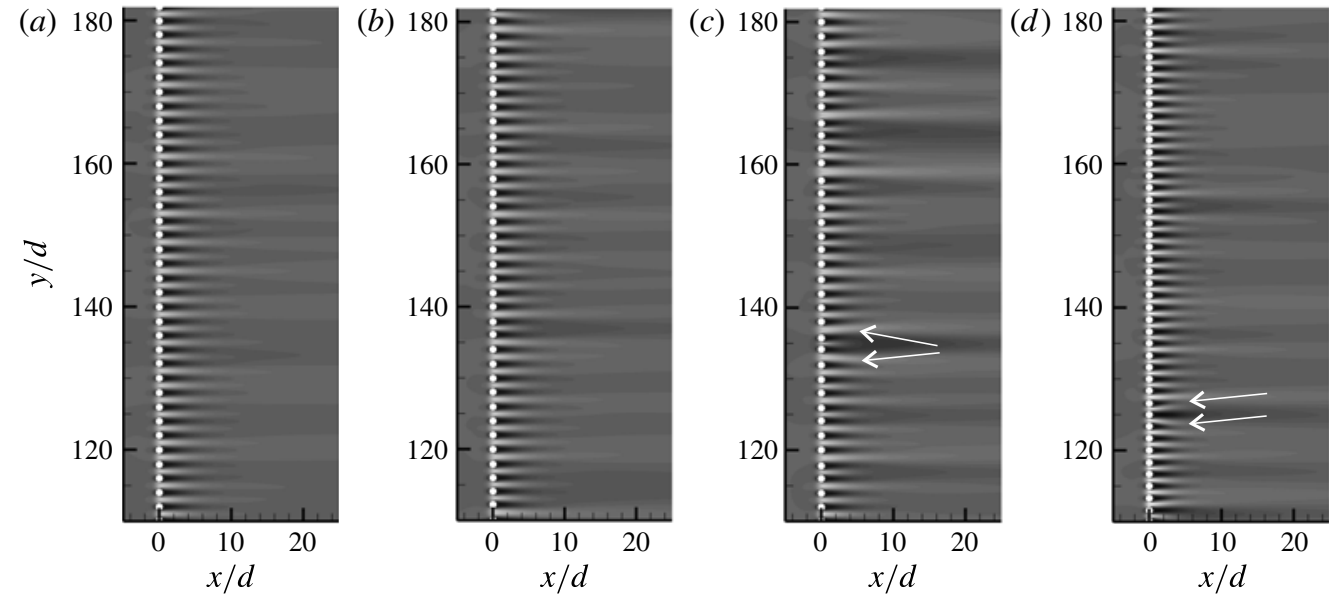

$(\Delta u)$

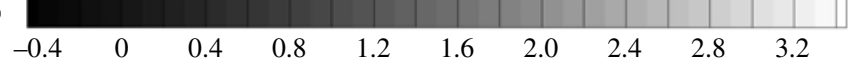

FIGURE 10. Contours of streamwise velocity scaled by free-stream velocity $U$ (see insert for scale) for limited extent $(<10 \%)$ of the zithers: $(a) \beta=50 \%$ with $\sigma_{\delta}=0.025, \sigma_{\epsilon} / \sigma_{\delta}=$ 0.13 ; (b) $\beta=50 \%$ with $\sigma_{\delta}=0.05, \sigma_{\epsilon} / \sigma_{\delta}=0.14$; (c) $\beta=50 \%$ with $\sigma_{\delta}=0.075, \sigma_{\epsilon} / \sigma_{\delta}=$ 0.18 ; (d) $\beta=40 \%$ with $\sigma_{\delta}=0.025, \sigma_{\epsilon} / \sigma_{\delta}=0.29$. Arrows indicate examples of significant jet deflection.

a limited number of jets in the $\beta=40 \%$ and to a lesser extent the $\beta=50 \%$ with $\sigma_{\delta}=0.075$ zithers. This differs from the flow visualisations of Bradshaw (1965) and Le Gal et al. (1996) where the majority of jets show large deflection. 

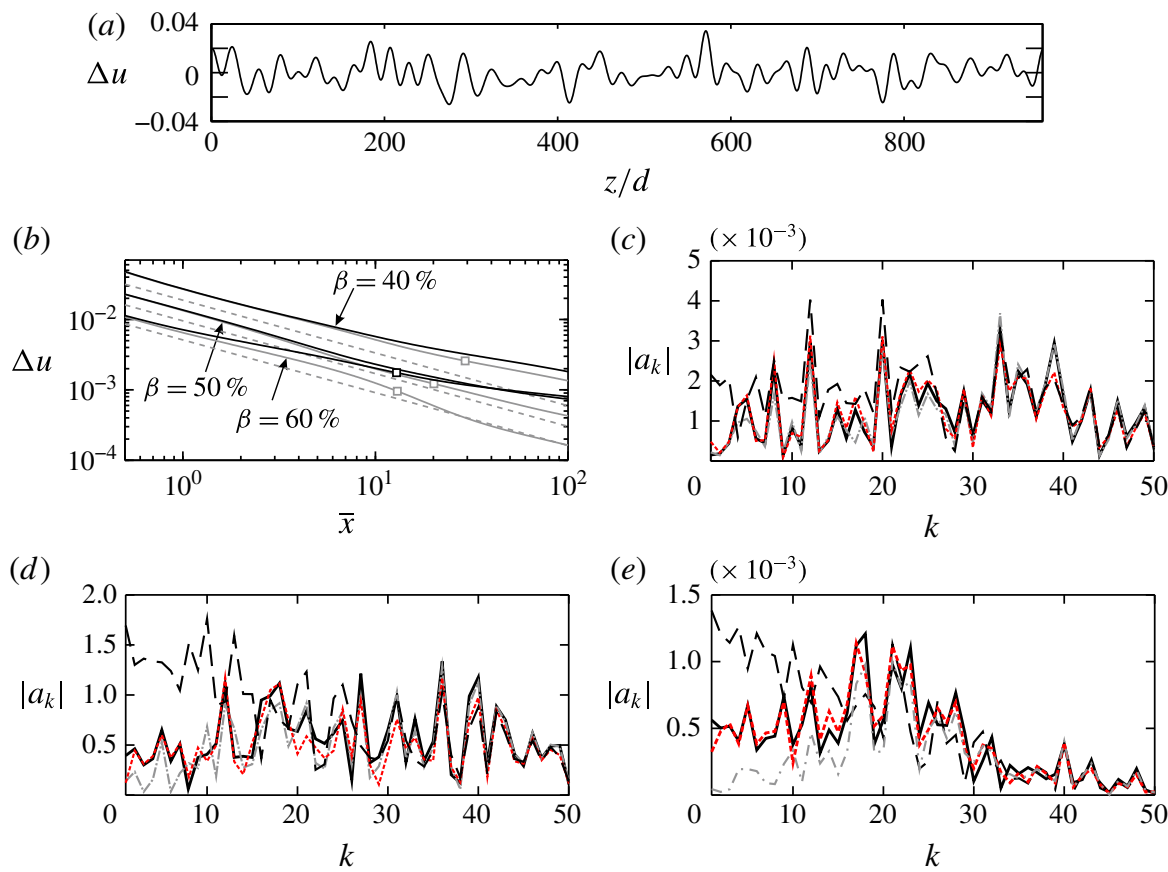

FIgURE 11. (Colour online) (a) Non-uniform velocity inlet profile. (b) Wake strength, $\beta=40 \%, 50 \%, 60 \%$ with $\sigma_{\delta}=0.025$ zithers. Dark solid line (stronger far wake) is non-uniform inflow. Light solid line is uniform inflow. Square makers indicated strength downstream calculated with (2.2). Dashed lines are (2.17). (c) Fourier coefficients at $\bar{x}=10$ for $\beta=40 \%$. (d) Fourier coefficients at $\bar{x}=10$ for $\beta=50 \%$. (e) Fourier coefficients at $\bar{x}=10$ for $\beta=60 \%$. Lines: black solid, extracted from CFD with non-uniform inflow; grey dash-dot, extracted from CFD with uniform inflow; black long-dash, calculated with (2.8) at zither and transferred to $\bar{x}=10$ with (2.5); red short-dash, calculated with (2.25) at zither and transferred to $\bar{x}=10$ with $(2.5)$.

\subsection{The effect of non-uniform inflow}

Limited CFD simulations are performed with a random inlet-velocity wake $\left(U_{r}\right)$, constructed by the addition of sinusoids, from $k=1$ to 50 , with random phase,

$$
U_{r}=U+\sum_{k=1}^{50} 0.002 U \sin \left(\frac{2 \pi k}{960} \frac{z}{d}+\text { random phase }\right) .
$$

The non-uniform inflow strength is $\Delta u=1 \%$ and the profile is shown in figure 11(a). The non-uniform inflow is applied to the $\beta=40 \%, 50 \%$ and $60 \%$ zithers with $\sigma_{\delta}=0.025$. The streamwise domains of the $\beta=40 \%$ and $50 \%$ zithers are extended to capture any change of wake decay.

Velocity contours near the zither (not shown) are not discernibly different to the uniform inflow simulations. For small $\bar{x}$, figure $11(b)$ shows the non-uniform inflow wake decay changes from $\bar{x}^{-0.75}$ towards $\bar{x}^{-0.25}$. This is readily apparent for the $\beta=$ $60 \%$ zither. For $\bar{x}>13$, the $\beta=60 \%$ zither wake is stronger than the $\beta=50 \%$ zither.

At $\bar{x}=10$, the $\beta=60 \%$ zither non-uniform inlet wake strength is $50 \%$ greater relative to a uniform inflow. The $\beta=50 \%$ zither wake is $16 \%$ greater and the 
$\beta=40 \%$ zither is only $9 \%$ greater. Standard deviations of wire source strength $\left(\sigma_{\epsilon}\right)$ for the $\beta=40 \%, 50 \%$ and $\beta=60 \%$ zithers are $0.0093,0.0045$ and 0.0058 , respectively. As $\sigma_{\delta}$ is the same, the combined wake-strength equation (2.15) would predict the $\beta=40 \%$ zither wake to show a greater deviation from $\bar{x}^{-0.75}$, opposite to what is observed in figure $11(b)$.

Wake Fourier coefficients at $\bar{x}=10$ are extracted from the CFD simulations and shown in figure $11(c-e)$ for the uniform and non-uniform inlet simulations. Also shown are the Fourier coefficients calculated from the individual wire drag and position data, and transferred to $\bar{x}=10$ by (2.5). The extracted Fourier coefficients at low wavenumbers are significantly smaller than calculated with wire position and drag data. This increases the calculated value of $\sigma_{\epsilon}$ relative to that observed. Decreasing open-area ratio reduces the difference between uniform and non-uniform inflow Fourier coefficients. The drag variation induced at the zither by the non-uniform inflow, creates an additional wake component tending to cancel the non-uniform inflow. The removal of a non-uniform inflow with increasing screen pressure drops is predicted by the Taylor \& Batchelor (1949) analysis. Hence, the far wake strength of the lower-open area ratio zithers with a non-uniform inflows differs less compared to a uniform inflow.

Prediction of the far wake with known wire position and drag data can be improved by linearly adding the non-uniform inlet velocity. The Fourier coefficients at the zither are then found as,

$$
a_{k}=\frac{\bar{q}}{L} \sum_{n=1}^{N}\left(-2 \pi \mathrm{i} K \delta_{n}+\epsilon_{n}-2 \pi \mathrm{i} K \epsilon_{n} \delta_{n}\right) \exp (-2 \pi \mathrm{i} K n)-a_{k w},
$$

where $a_{k w}$ is the $k$ th Fourier coefficient of the non-uniform inflow at the zither, assuming no influence of the zither. It is subtracted due to the convention of a wake being positive. Figure 11(c-e) reveals the addition of the non-uniform inflow term produces good agreement between the calculated and CFD Fourier coefficients.

\section{Zither wakes through the contraction}

The zither wakes of normal vorticity pass through a contraction which removes the majority of the $\Delta u$ wake component and produces streamwise vorticity. The uniform-inflow zither wakes are sampled 197d downstream of the zither and imposed $957 d$ upstream of the contraction start. Symmetry requires only the lower-half of the 5:1, two-dimensional contraction to be modelled. A structured mesh with quadrilateral $\mathrm{CV}$ is used, with 440,200 and $500 \mathrm{CV}$ in the streamwise, wall-normal and spanwise directions. This is the same geometry and similar mesh resolution used by Pook \& Watmuff (2014) to accurately reproduce the effect of a single wire wake passing through a contraction by comparison with the experiment of Watmuff (2006).

Figure 12 provides an example of a two-dimensional zither wake entering the contraction and contours of the streamwise vorticity $\left(\omega_{x}\right)$ on a plane $394 d$ downstream of the exit, scaled by the standard deviation of the normal vorticity entering the contraction $\left(\sigma_{\omega y \text { in }}\right)$. The contraction floor is located at $y / d=0$ on the downstream plane and the leading edge used in $\S 4$ is located at $y=186 d$. Stronger regions of streamwise vorticity near the contraction floor are due to the combination of Görtler instability near the no-slip contraction wall combined with the tilting and stretching mechanism discussed by Pook \& Watmuff (2014). The visible wake spanwise wavelength changes little through the contraction. The magnitude of the streamwise vorticity reduces to zero at the contraction centreline. 
(a)

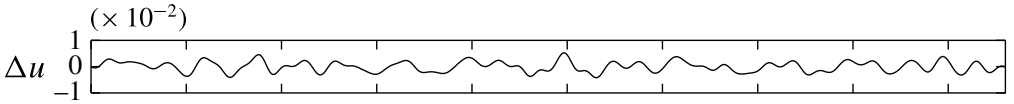

(b)

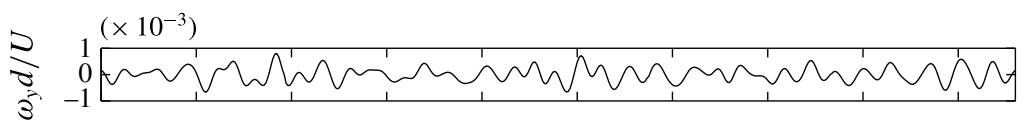

(c)

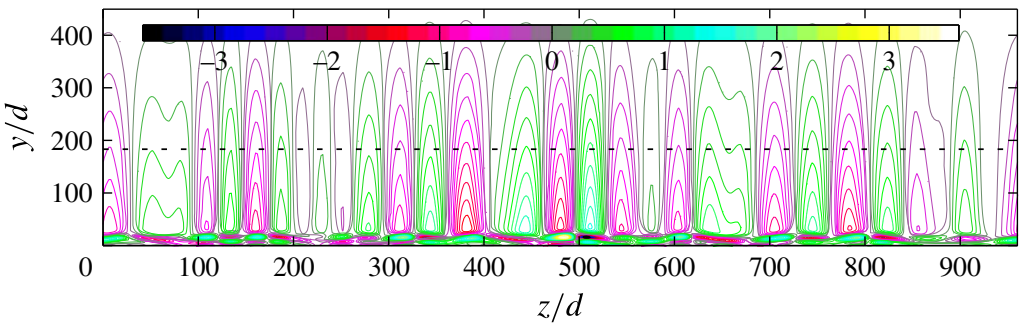

FIgURE 12. (Colour online) Wake of the $\beta=50 \%$ with $\sigma_{\delta}=0.025$ zither entering the contraction and streamwise vorticity out. (a) Wake spanwise profile of $\Delta u$ entering contraction. (b) Wake spanwise profile of normal vorticity $\left(\omega_{y}\right)$ entering contraction. (c) Contours of streamwise vorticity $\left(\omega_{x} / \sigma_{\omega y i n}\right), 394 d$ downstream of the contraction exit. Dashed line is leading edge of $\S 4$.
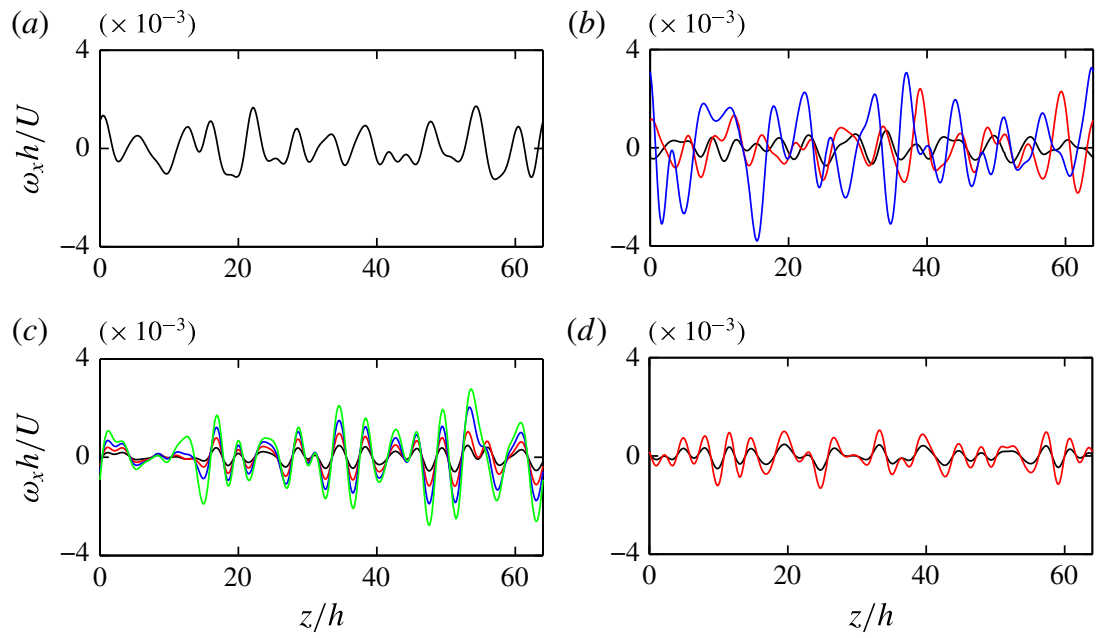

FIgURE 13. (Colour online) Streamwise vorticity 394d downstream of the contraction exit, $186 d$ above the contraction floor: (a) $\beta=40 \%$; (b) $\beta=50 \%$; (c) $\beta=60 \%$; (d) $\beta=66.67 \%$. Lines: black, $\sigma_{\delta}=0.025$; red, $\sigma_{\delta}=0.05$; blue, $\sigma_{\delta}=0.075$; green, $\sigma_{\delta}=0.1$.

A spanwise profile of streamwise vorticity at the contraction exit is shown in figure 13. The zither with the strongest wake, $\beta=50 \%$ with $\sigma_{\delta}=0.075$, produces the strongest streamwise vorticity. The maximum streamwise velocity perturbation on a spanwise profile 11 leading edge half-thicknesses $(h)$ upstream of the leading edge, is less than $0.015 \%$ of $U$ (not shown). The streamwise vorticity is predominantly due to spanwise variation of the wake normal velocity perturbation (maximum of $\sim 0.5 \%$ of $U$ ), giving a flow angle of $0.26^{\circ}$. However, the standard deviation of the 

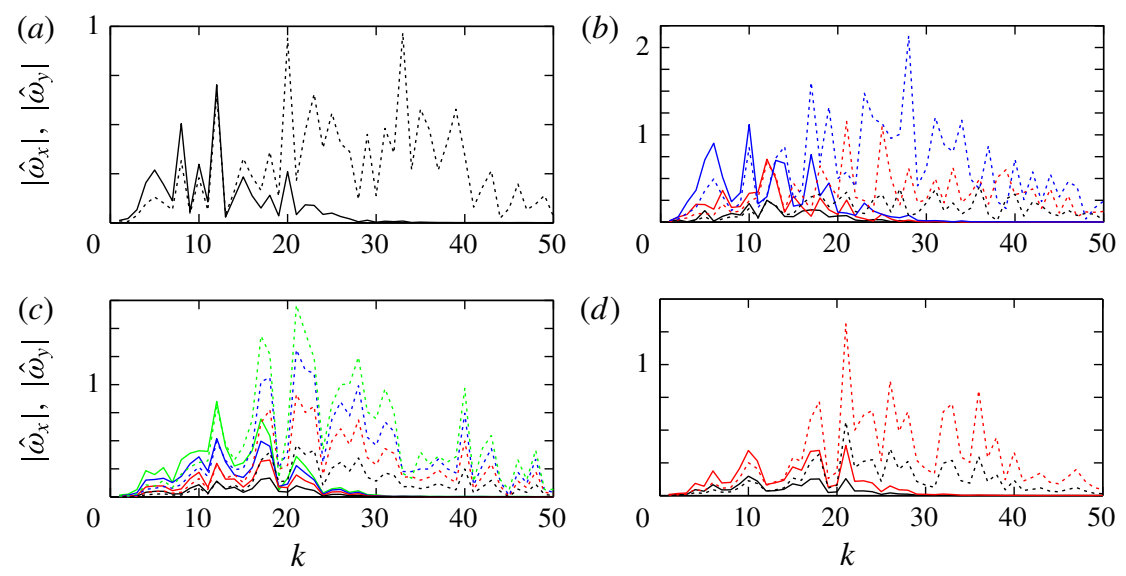

FIGURE 14. (Colour online) Streamwise vorticity FFT ( $\hat{\omega}_{x}$, solid lines) magnitude, 394d downstream of the contraction exit, $186 d$ above the contraction floor. Normal vorticity $\left(\hat{\omega}_{y}\right.$, dotted lines) magnitude at contraction start. (a) $\beta=40 \%$; (b) $\beta=50 \%$; (c) $\beta=60 \%$; (d) $\beta=66.67 \%$. Lines: black, $\sigma_{\delta}=0.025$; red, $\sigma_{\delta}=0.05$; blue, $\sigma_{\delta}=0.075$; green, $\sigma_{\delta}=0.1$.

flow angle is only $0.1^{\circ}$ and is a better indicator of what would be measured by a survey of flow quality.

An FFT on the spanwise profile of streamwise vorticity exiting, and normal vorticity entering, is shown in figure 14 . The largest streamwise vorticity coefficient occurs at $k=10-12$ for all zithers, except the $\beta=66.67 \%$ zithers which have three peaks from $k=11$ to 21 . At this height above the floor, wavenumbers below $k \approx 10$ exhibit a larger streamwise vorticity Fourier coefficient than the normal vorticity, while for $k>30$ the coefficients are negligible at the contraction exit.

Table 2 lists the standard deviation of the normal vorticity entering the contraction $\left(\sigma_{\omega y \text { in }}\right)$, and the standard deviation of the streamwise vorticity on the spanwise profile after the contraction, at the height of the leading edge to be used in $\S 4,\left(\sigma_{\omega x \text { out }}\right)$. The ratio varies between 0.30 and 0.45 , increasing with a decrease in screen open-area ratio and increase in $\sigma_{\delta}$. This indicates differing wake decay rates in the contraction.

The zither wake decay through the contraction $\left(\Delta u_{c}\right)$ is examined with the ratio,

$$
\Delta u_{c}=\frac{\Delta u_{\text {local }}}{\Delta u_{0}},
$$

where $\Delta u_{\text {local }}$ is the wake strength on the contraction centreline normalised by the local velocity on the contraction centreline, and $\Delta u_{0}$ is the zither wake strength at the contraction entry. Figure 15 plots (3.1). At the contraction exit, the value of $\Delta u_{c}$ for the strongest zither wake is twice that of the weakest. Zithers with relatively larger low-wavenumbers of drag variation (see figure 7) have a stronger wake exiting the contraction, indicating the importance of large-wavelength drag variation across the zither. The trend in figure 15 holds across a contraction cross section.

\section{Test section flat-plate boundary layer}

The streamwise vorticity exiting the contraction creates streaks in the test-section plate boundary layer. Receptivity to low-frequency streamwise vorticity has been 


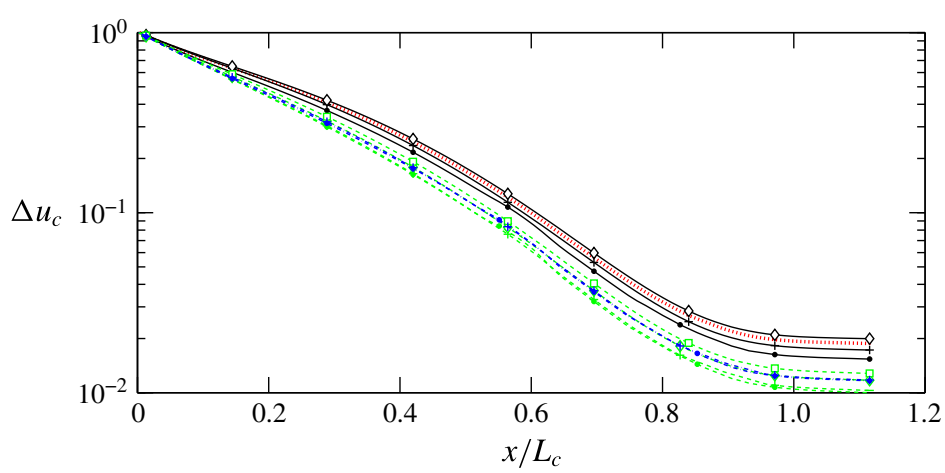

FIGURE 15. (Colour online) Scaled wake strength on the contraction centreline, $\Delta u_{\text {cont }}$ defined by (3.1). The contraction curvature begins at $x / L_{c}=0$ and ends at $x / L_{c}=1, L_{c}=$ $1.524 \mathrm{~m}$. Lines: $\ldots$ $0.05 ; \multimap \beta=50 \% \quad \sigma_{\delta}=0.075 ;-\bullet-\beta=60 \% \quad \sigma_{\delta}=0.025 ;-+-\beta=60 \% \quad \sigma_{\delta}=0.05 ; \leftrightarrow \diamond-$ $\beta=60 \% \quad \sigma_{\delta}=0.075 ; \quad-\square-\beta=60 \% \quad \sigma_{\delta}=0.1 ; \ldots \bullet \beta=66 \% \quad \sigma_{\delta}=0.025$.

\begin{tabular}{|c|c|c|c|c|c|}
\hline$\beta(\%)$ & $\sigma_{\delta}$ & $\sigma_{\Delta u i n}(\%)$ & $\sigma_{\omega y \text { in }}\left(\mathrm{s}^{-1}\right)$ & $\sigma_{\omega x \text { out }}\left(\mathrm{s}^{-1}\right)$ & $\sigma_{\omega x \text { out }} / \sigma_{\omega y \text { in }}$ \\
\hline 40.00 & 0.025 & 0.41 & 3.62 & 1.57 & 0.43 \\
\hline 50.00 & 0.025 & 0.20 & 1.90 & 0.73 & 0.38 \\
\hline 50.00 & 0.050 & 0.46 & 4.04 & 1.81 & 0.45 \\
\hline 50.00 & 0.075 & 0.88 & 7.56 & 3.28 & 0.43 \\
\hline 60.00 & 0.025 & 0.19 & 1.78 & 0.54 & 0.30 \\
\hline 60.00 & 0.050 & 0.37 & 3.53 & 1.08 & 0.31 \\
\hline 60.00 & 0.075 & 0.55 & 5.16 & 1.75 & 0.34 \\
\hline 60.00 & 0.100 & 0.74 & 6.72 & 2.49 & 0.37 \\
\hline 66.67 & 0.025 & 0.17 & 1.65 & 0.51 & 0.31 \\
\hline 66.67 & 0.050 & 0.36 & 4.03 & 1.31 & 0.32 \\
\hline
\end{tabular}

TABLE 2. Ratio of $\sigma_{\omega x \text { out }}$ to $\sigma_{\omega y \text { in }}$ on a profile $394 d$ downstream of contraction exit and $186 d$ above contraction floor.

shown by Schrader et al. (2010) to be a dominant mechanism. The same leading edge geometry as Pook \& Watmuff (2014) with a slot mass-flow of 0.21 is used (see Pook \& Watmuff (2014) for details). Near Blasius flow is achieved by $R=400$, where $R=\sqrt{U x / \nu}$, as indicated by the shape factor in figure 16 . The virtual origin is small and of little consequence to the results presented. Shifting the attachment point has a minimal effect on the receptivity to streamwise vorticity (Pook \& Watmuff 2014). The free-stream velocity over the flat-plate region is $U=8.6 \mathrm{~m} \mathrm{~s}^{-1}$.

The mesh in the test-section boundary layer has minimal skewness with $\sim 40 \mathrm{CV}$ in the wall-normal direction and $\sim 500 \mathrm{CV}$ in the spanwise direction. The total mesh size is $\sim 45$ million CV. This is a similar level of refinement as $\mathrm{Mesh}_{2}$ in Pook \& Watmuff (2014) that was shown to accurately calculate the streak strength.

\subsection{Measures of streak strength}

Various measures of streak strength have been favoured in the literature with no direct relations provided between them. Figure $17(a)$ documents streak strength $\left(\Delta \delta^{*}\right)$ as 


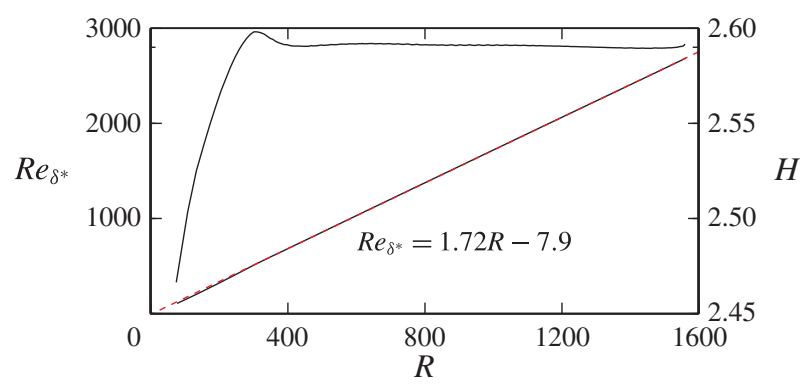

FIgURE 16. (Colour online) Two-dimensional base flow. Reynolds number based on displacement thickness $\left(R_{\delta^{*}}\right)$ versus $R$ and shape factor $(H)$ versus $R$. Blasius displacement thickness growth shown with - - -. Equation is fit to CFD data. The leading edge ends at $R=345$.
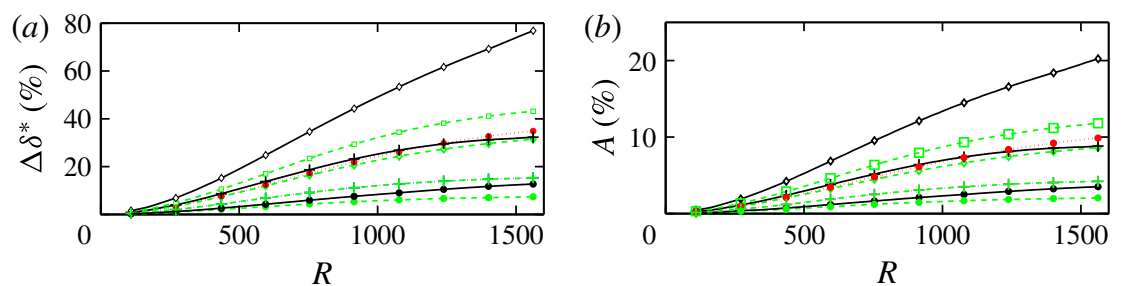

FIgURE 17. (Colour online) (a) Streak strength $\Delta \delta^{*}$ versus $R$. (b) Streak amplitude $(A)$ versus $R$. Lines and markers as for figure 15 .

measured by the maximum and minimum displacement thickness on a given crosssectional plane,

$$
\Delta \delta^{*}=\frac{\max _{y, z}\left(\delta^{*}\right)-\min _{y, z}\left(\delta^{*}\right)}{\delta_{b}^{*}},
$$

where the subscript $b$ indicates the two-dimensional flow with no streaks. Figure $17(b)$ shows the corresponding streak amplitude $(A)$ defined by,

$$
A=\frac{\max _{y, z}\left(U-U_{b}\right)-\min _{y, z}\left(U-U_{b}\right)}{2 U} .
$$

Both measures are linear with $x^{0.5}$, downstream of an initial receptivity region, until $R \approx 1000$.

The ratio of $\Delta \delta^{*}$ to $A$ beyond $R>400$ is approximately 3.6 for all zithers except the $\beta=40 \%$ with $\sigma_{\delta}=0.075$ and $\beta=50 \%$ with $\sigma_{\delta}=0.075$ zithers. For these zithers, the ratio varies between 3.5 and 3.8 with increasing $R$. These zithers have larger amplitude Fourier modes at low wavenumbers. The optimal non-modal growth theory of Andersson et al. (1999) and Luchini (2000) explains that larger spanwise wavelength disturbances will exhibit greater growth and peak further downstream. Indeed, the $\beta=50 \%$ with $\sigma_{\delta}=0.075$ zither generates the largest streak growth by a substantial margin with a peak beyond the streamwise domain $(R>1600)$. The growth of the weaker zither streaks can be seen to be slowing towards the end of the streamwise domain. 

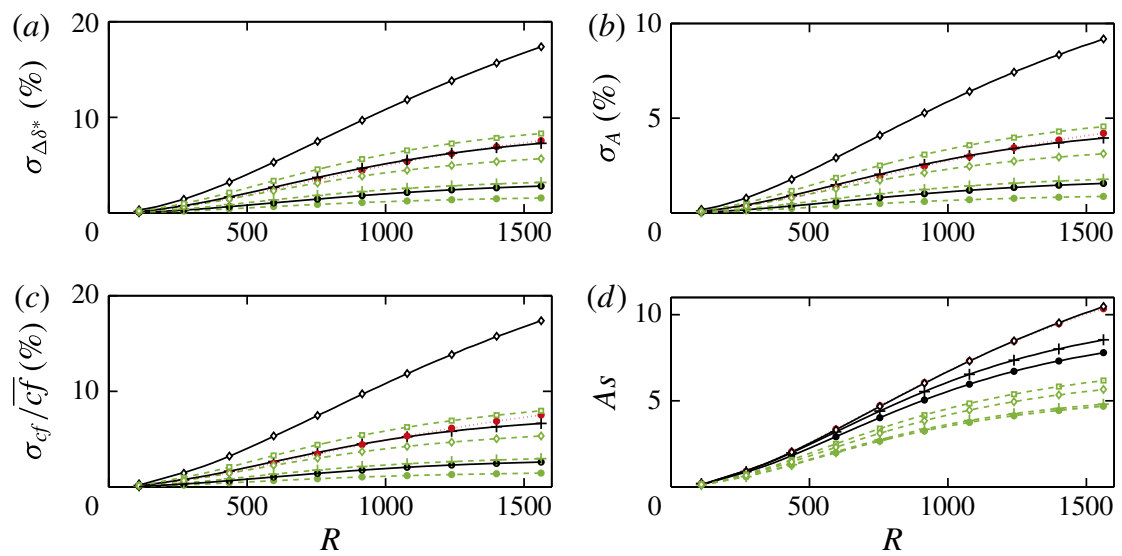

FIGURE 18. (Colour online) (a) Standard deviation of streak strength $\sigma_{\Delta \delta^{*}}$ versus $R$. (b) Standard deviation of streak amplitude $\sigma_{A}$ versus $R$. (c) Standard deviation of normalised skin friction $\sigma_{c f} / \overline{c f}$ versus $R$. (d) Streak strength scaled to zither wake before contraction $(A s)$ versus $R$. Lines and markers as for figure 15.

The streak growth qualitatively agrees with the compiled Klebanoff streak data of Westin et al. (1994), which shows linear growth with $x^{0.5}$. Only three data-sets extend beyond $R=1500$, with one set showing a peak and then decrease downstream while the other two show a rapid increase which probably indicates transition. Note the experimental measures of Klebanoff streaks are $u_{r m s}$ and not directly the streak amplitude measured here.

Streak strength and amplitude as defined are measures of minimum and maximum deviation from the two-dimensional layer. The standard deviation of these quantities for steady streaks is likely to have a closer relation to the experimental measures of unsteady streaks (e.g. $u_{r m s}$ ) and any possible correlation with TS-wave suppression. The standard deviation of streak strength and amplitude are shown in figure 18. The standard deviation of streak strength $\left(\sigma_{\Delta \delta^{*}}\right)$ at a given streamwise plane is defined by,

$$
\sigma_{\Delta \delta^{*}}=\frac{1}{\delta_{b}^{*}} \sqrt{\frac{1}{L} \int_{0}^{L} \delta^{* 2} \mathrm{~d} z}
$$

and the standard deviation of streak amplitude $\left(\sigma_{A}\right)$ by,

$$
\sigma_{A}=\sqrt{\frac{1}{U^{2} L} \int_{0}^{L} \max _{y, z}\left(U-U_{b}\right)^{2} \mathrm{~d} z} .
$$

The standard deviation measures are significantly less than the maximal measures but the same relative trends are observed.

Skin friction also provides a measure of streak growth. Figure 18 shows the variation in skin friction defined by,

$$
\begin{aligned}
\sigma_{c_{f}}=\frac{2 v}{U^{2}} \sqrt{\frac{1}{L} \int_{0}^{L}\left(\frac{\partial U}{\partial y}-\frac{\overline{\partial U}}{\partial y}\right)^{2} \mathrm{~d} z}, \quad \overline{c_{f}} & =\frac{2 v}{U^{2}} \frac{\overline{\partial U}}{\partial y}, \quad \frac{\partial U}{\partial y}=\frac{1}{L} \int_{0}^{L} \frac{\partial U}{\partial y} \mathrm{~d} z \\
\Delta c_{f} & =\frac{\sigma_{c_{f}}}{\overline{c_{f}}}
\end{aligned}
$$


where $\Delta c_{f}$ is the ratio of skin-friction standard deviation to the spanwise mean value, and the wall-normal velocity gradients are measured at the wall. The ratio of $\Delta c_{f}$ to $\sigma_{A}$ is not constant, varying between 1.65 and 1.9 for the current zither streaks. Skin friction varies between $1.5 \%$ and $18 \%$ at $R=1550$, an order of magnitude variation. Bradshaw (1965) found turbulent skin-friction variation exceeding $10 \%$ when screens with $\beta<57 \%$ were installed. Only the $\beta=50 \%$ with $\sigma_{\delta}=0.075$ zither exceeds $10 \%$.

Based on the magnitude of skin-friction variation for the $\beta=50 \%$ with $\sigma_{\delta}=0.075$ zither, it seems likely that the cause of the spanwise variation in the results of Bradshaw (1965) is also present in the current simulations. Bradshaw (1965) attributed the variation to a spatial 'instability' downstream of the screen, leading to the coalescence of jets. The current simulations suggest the cause can be interpreted as being due to the variation of wire drag and wire position across the zither.

\subsection{Streak amplitude related to the zither}

Ideally, a simple relation can be found to relate streak amplitude to the zither geometry. Relating streak growth to a single measure of velocity variation in the wake will fail, as streak growth is strongly dependent on spanwise wavelength. The relation must be made in terms of vorticity and consider the spectral distribution. However, the current zither wakes do share a similar spanwise wavelength as the zither position is constant and the zither wake wavelength formula was found to be accurate (see figure 8). The contraction and leading edge geometry are also identical. Thus, the streak amplitude can be scaled by the wake strength entering the contraction. If all zither wakes maintain the same wake decay rate, and the streak growth in the test-section layer is linear with amplitude, then a measure of streak amplitude scaled by a measure of the zither wake entering the contraction should collapse to a single curve. Figure 18(d) shows the standard deviation of streak amplitude $\left(\sigma_{A}\right)$ scaled by the standard deviation of the zither wake strength entering the contraction $\left(\sigma_{\Delta u / U \text { in }}\right)$,

$$
A s=\frac{\sigma_{A}}{\sigma_{\Delta u / U i n}} .
$$

The $\beta=66.67 \%$ and $\beta=60 \%$ zithers with $\sigma_{\delta}=0.025$ and $\sigma_{\delta}=0.05$ streak growth collapses with this scaling. However, the $\beta=60 \%$ zithers with $\sigma_{\delta}=0.075$ and $\sigma_{\delta}=0.1$ show an increased scaled streak growth. This indicates a stronger wake, due to a reduced wake decay rate far downstream of the zither. Decreasing $\beta$ for a given $\sigma_{\delta}$ also increases the scaled streak growth. This is highlighted by the $\beta=40 \%$ with $\sigma_{\delta}=0.025$ and $\beta=50 \%$ with $\sigma_{\delta}=0.075$ zithers that have nearly identical scaledstreak-growth. Their scaled-streak-amplitude is more than double that for the $\beta=$ $66.67 \%$ with $\sigma_{\delta}=0.05$ zither at $R=1500$. Although the dominant Fourier mode in the wake is of a similar wavelength, the spectral distribution is not. Figure 14 shows they have larger amplitude Fourier coefficients below $k=10$, creating larger streaks further downstream. A simple relation between the zither wake strength and the streak amplitude cannot be found.

\subsection{Spanwise mean quantities}

Figure 19(a) shows the zither streaks have a negligible effect on the spanwise mean displacement thickness, consistent with experimental observations of Klebanoff streaks (Westin et al. 1994). However, figure 19(b) reveals the mean shape factor decreases with streamwise distance relative to the two-dimensional layer. Stronger streaks 

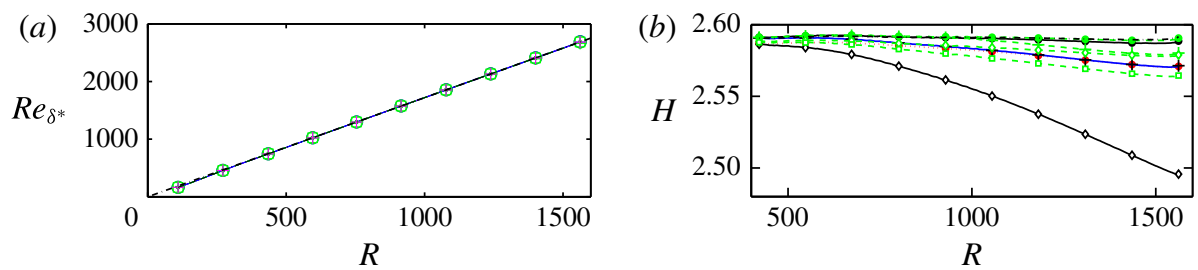

FIGURE 19. (Colour online) (a) Spanwise mean displacement thickness versus $R$. (b) Spanwise mean shape factor $(H)$ versus $R .-\cdot-\cdot-$ Two-dimensional base-flow. Other lines and markers as for figure 15.

produce a greater decrease. Westin et al. (1994) reported a decreasing shape factor when FST induced Klebanoff streaks are present, observing a shape factor of 2.41 at $R=1260$. Only the $\beta=50 \%$ with $\sigma_{\delta}=0.075$ zither produces a comparable mean shape factor but it occurs further downstream.

\subsection{Streak wall-normal velocity profiles}

Streaks cause a deviation in the velocity profile relative to the undisturbed twodimensional base flow. The deviation at a given spanwise position is defined by,

$$
\frac{\Delta U}{U_{e}}=\frac{U-U_{b}}{U_{e}},
$$

where $U_{e}$ is the edge velocity of the layer. Figure 20 shows zither streak profiles at $R=1350$ and a given spanwise position are either all in excess or decrement. The spanwise average of the profiles exhibits an 's'-shape, except for the $\beta=60 \%$ with $\sigma_{\delta}=0.025$ and $\sigma_{\delta}=0.05$ zither streaks that have a slight excess across the layer. The 's'-shape develops further downstream when the streak amplitude increases. From figure 20, increasing $\sigma_{\delta}$ (which increases streak amplitude) increases the magnitude of the 's'-shape maximum (lower part of 's') and minimum (upper part of ' $s$ '), approximately 30-fold for the $\beta=50 \%$ streaks. With increasing $\sigma_{\delta}$, the 's'-shape maximum moves towards the wall, and the minimum away. This is due to the maximum of local profiles in excess shifting towards the wall, and the minimum of profiles in decrement away. This agrees with the simulations by Jacobs \& Durbin (2001) where backwards jets (unsteady streaks) are lifted to the boundary-layer edge prior to breakdown, and the PIV of Nolan \& Walsh (2012) that observed the excess maximum to move towards the wall while the low-speed streak moves away.

The 's'-shaped mean profile is similar to the observations of time-averaged, Klebanoff streaks made by Westin et al. (1994) using a grid in the test section to elevate the FST. At $R=1350$ the maximum of the 's'-shape for the $\beta=50 \%$ with $\sigma_{\delta}=0.075$ zither streaks is approximately $\max \left(\Delta U / U_{e}\right) \approx 0.01$ and the mean shape factor is 2.52 , similar to Westin et al. (1994) $\left(\max \left(\Delta U / U_{e}\right) \approx 0.011\right.$ when $H=2.53)$. However, Kendall $(1985,1998)$ measured time-averaged velocity profiles in the presence of Klebanoff streaks at $R=980$, with FST elevated by a grid upstream of the contraction, to be in decrement across the entire layer $\left(\min \left(\Delta U / U_{e}\right) \approx-0.02\right)$. The zither streak results combined with Westin et al. (1994) suggest the difference cannot be attributed solely to a grid location upstream of the contraction. 

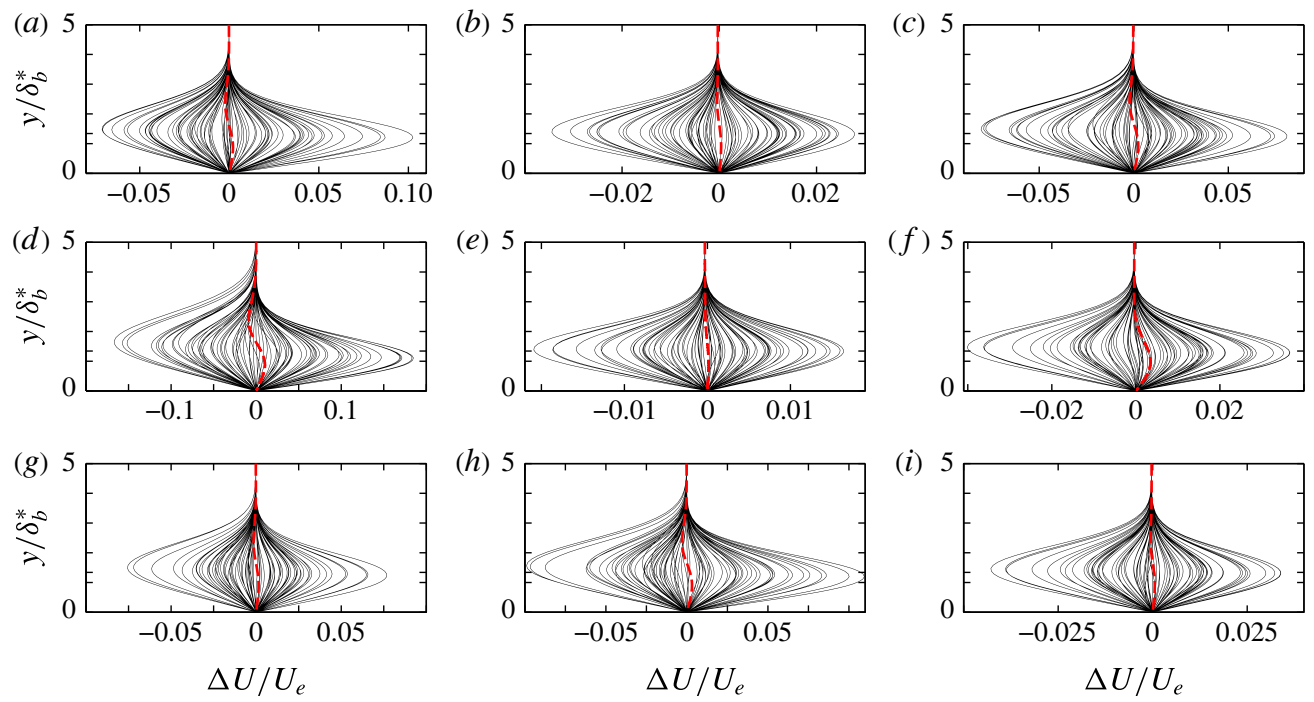

FIgURE 20. (Colour online) Wall-normal profiles of $\Delta U / U_{e}$, defined by (4.8), at various spanwise positions and $R=1350$. Lines: $-\Delta U / U_{e}$ at some spanwise position; -- spanwise mean. (a) $\beta=40 \%, \sigma_{\delta}=0.025$; (b) $\beta=50 \%, \sigma_{\delta}=0.025$; (c) $\beta=50 \%$, $\sigma_{\delta}=0.050 ;(d) \beta=50 \%, \sigma_{\delta}=0.075 ;(e) \beta=60 \%, \sigma_{\delta}=0.025 ;(f) \beta=60 \%, \sigma_{\delta}=0.050$; (g) $\beta=60 \%, \sigma_{\delta}=0.075$; (h) $\beta=60 \%, \sigma_{\delta}=0.100$; (i) $\beta=66.67 \%, \sigma_{\delta}=0.025$.

\section{Zither streak linear stability}

The analysis suggests the zither streaks share many similarities with Klebanoff streaks, but are steady. If transition is to be predicted accurately in differing wind tunnels, then the methodology must be able to predict transition for the current zither streak base flows. Watmuff (1998) observed that initial flow quality improvements related to the settling chamber screens shifted the transition location upstream to a distance $67 \%$ of that observed before the improvements. The computational results of Cossu \& Brandt (2004) for the optimal streak would suggest that transition was promoted in the Watmuff (1998) wind tunnel as TS-wave growth was previously damped by the presence of streaks. However, Vaughan \& Zaki (2011) found steady, free stream forced streaks with amplitudes $\lesssim 15 \%$ can increase TS-wave growth rates. These studies did not use streaks generated from a realistic free-stream disturbance. Parabolized stability equations in three-dimensions (PSE-3D) will be used to assess the linear stability of the zither streak base flows.

PSE-3D is an extension to traditional PSE that allows spanwise variation of the base flow, first presented by Broadhurst \& Sherwin (2008). A monochromatic disturbance is described by the product of a shape function on a cross-stream plane, and a spatially growing wave component with a complex streamwise wavenumber $(\alpha)$. The streamwise wavenumber is adjusted marching downstream to keep the total energy of the shape-function constant. A BiGlobal eigenvalue problem provides the initial condition. Details of the numerical implementation can be found in Pook (2013). Unless noted, Chebyshev polynomials are used to difference stability equations in the wall-normal direction with 70 collocation points, and $k=25$ Fourier modes are used in the spanwise direction. First-order upwind differencing is used in the streamwise direction. 
Conceptually, the PSE-3D can be used with the $\mathrm{e}^{N}$ method in place of the Orr-Sommerfeld or two-dimensional PSE equations. This would require a database of streaky base-flow transition results and would inherit all the limitations and assumptions of the $\mathrm{e}^{N}$ method, with no guarantee it will be as successful.

\subsection{Two-dimensional base-flow linear stability}

The linear stability of the two-dimensional base-flow can be measured by the $\mathrm{N}$-factor, the ratio of disturbance amplitude growth from Branch 1, which is the streamwise position when the disturbance first becomes unstable. The $N$-factor is defined by,

$$
N \text {-factor }=\int_{\text {Branch } 1}^{x} \alpha_{i}(\zeta) \mathrm{d} \zeta .
$$

The CFD base flow is of sufficient accuracy to provide results of at least qualitative accuracy (see Pook 2013). A resolution check is performed later.

\subsection{BiGlobal resolution of the eigenvalue spectrum}

The $\beta=50 \%$ with $\sigma_{\delta}=0.075$ zither streak base flow at $R=940\left(R e_{\delta^{*}}=1615\right)$ is used to examine spanwise resolution requirements. The streak peak amplitude $(A)$ is $12.5 \%$ and the standard deviation of amplitude $\left(\sigma_{A}\right)$ is $5.4 \%$. The BiGlobal eigenvalue spectrum is investigated for a disturbance non-dimensional frequency, $F=65$ where,

$$
F=\frac{\omega \nu}{U^{2}} \times 10^{6} .
$$

The dimensional circular frequency is $326.8 \mathrm{rad}^{-1}$. For this frequency and position, the two-dimensional base flow is unstable (slightly upstream of Branch 2).

The BiGlobal spectrum, calculated using the modes $k=-5$ to 5 , is shown in figure $21\left(\alpha_{i}<0\right.$ indicates streamwise growth). The streaky base flow is not symmetric, which prevents using the even/odd assumption to reduce the eigenvalue problem size. The QZ eigenvalue solver (Matlab eig function) is used. The spectrum is similar in appearance to that of two-dimensional Blasius flow. The discrete approximation to the continuous modes can be seen to the left of the spectrum. The spread of the continuous modes is due to the wall-normal differencing not capturing the oscillations of the eigenvectors. Four unstable, discrete eigenvalues can be seen near $\alpha_{r} \delta_{b}^{*} \approx 0.3$.

The eigenvalue spectrum in the region of the unstable eigenvalues is resolved more accurately using an increasing number of spanwise modes and the Arnoldi eigenvalue solver (Matlab eigs function). The increased resolution produces a 'curved line' of discrete eigenvalues. Similar to the spectrum for TS modes with varying spanwise wavenumber on a two-dimensional base flow. The most unstable eigenvalue appears by itself. In the limit of two-dimensional flow, without providing direct proof, this mode would correspond to the two-dimensional TS mode. Tracking this mode back towards the leading edge (streak strength decreasing) produces an eigenvector with minimal spanwise variation and an eigenvalue close to that for the two-dimensional layer. It will be called the streaky TS mode following Cossu \& Brandt (2004) and labelled A in figure 21. The remaining eigenvalues can be seen to appear in pairs. In the limit of two-dimensional flow they would be the oblique TS modes. They are split because the streaky zither base flow is not spanwise symmetric. They will be called the streaky oblique TS modes and two examples are labelled B and C in figure 21. 


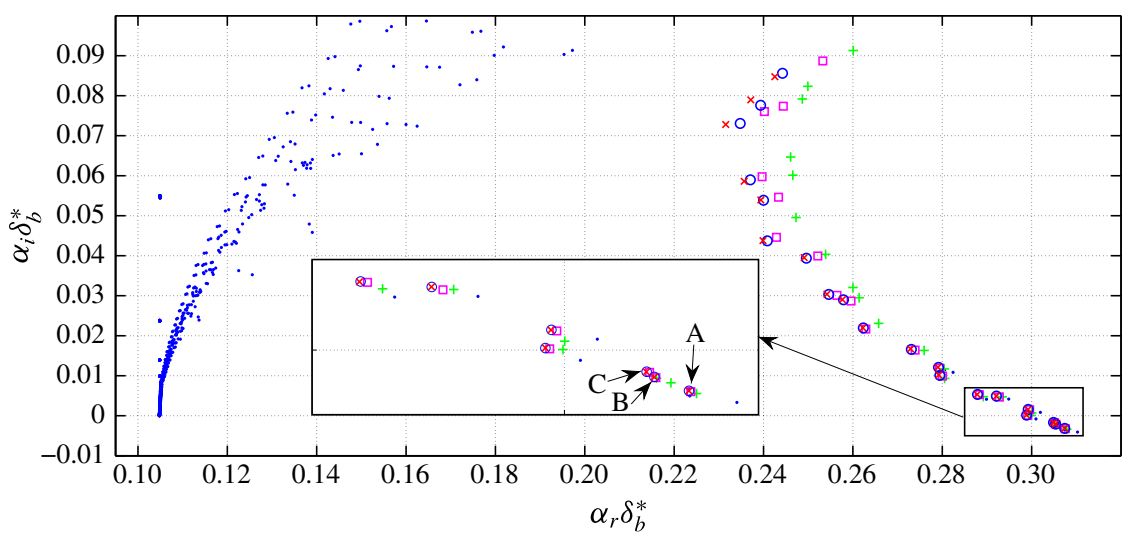

FIgURE 21. (Colour online) The effect of spanwise resolution (Fourier modes $k=-N$ to $N)$ on the eigenvalues for the $\beta=50 \%, \sigma_{\delta}=0.075$ zither at $\operatorname{Re}_{\delta^{*}}=1615(R=940)$. Perturbation frequency is $F=65, \omega=326.8 \mathrm{rad}^{-1}$. A is streak TS mode. B and C are first streaky oblique TS modes. Markers: $-N=5$ and QZ solver; $+N=10$ and Arnoldi Solver; $\square N=15$ and Arnoldi Solver; $\bigcirc N=20$ and Arnoldi Solver; $\times N=25$ and Arnoldi Solver.

$\begin{array}{lccccc}k & 5 & 10 & 15 & 20 & 25 \\ \alpha_{r} \delta_{b}^{*} & 0.3103 & 0.3079 & 0.3075 & 0.3074 & 0.3074 \\ \alpha_{i} \delta_{b}^{*} & -0.004075 \mathrm{i} & -0.003384 \mathrm{i} & -0.003237 \mathrm{i} & -0.003167 \mathrm{i} & -0.003171 \mathrm{i}\end{array}$

TABLE 3. Streaky TS-mode convergence with BiGlobal spanwise resolution.

The streaky oblique modes require increased resolution to resolve compared to the streaky TS mode. The convergence of the streaky TS-mode eigenvalue is shown in table 3. It does not change significantly beyond $k=20$. The majority of the streak base-flow energy is in modes $k \leqslant 15$.

The eigenvectors of labelled eigenvalues A, B and C are shown in figure 22. The $u_{r m s}$ maxima of the streaky TS is located in high-speed streak regions, while regions of increased $u_{r m s}$ for the streaky oblique TS are offset from each other in the spanwise direction but remain located in high-speed streak regions. The linear summation of the oblique modes is also shown in figure 22. The eigenvectors have been scaled to have the same total energy prior to addition. The majority of elevated $u_{r m s}$ for the combined streaky oblique modes is located to the left of $z / d=500$ while the streaky TS mode is most elevated in regions to the right of $z / d=500$. The maximum spanwise velocity component of the streaky oblique modes, $\sim 0.6 u_{r m s}$, is considerably higher than that for the streaky TS mode, $\sim 0.4 u_{r m s}$ (not shown). Increasing streak amplitude by decreasing zither open-area ratio or increasing $\sigma_{\epsilon}$, increases the distortion of the streaky TS relative to two-dimensional TS.

\subsection{Zither streak $N$-factor}

The effect of the zither wake on streaky TS growth and predicted transition is evaluated with $N$-factor curves. Disturbance frequencies $F=30,45,65$ are computed and shown in figure 23. The $F=30$ disturbance is also calculated using a base-flow 


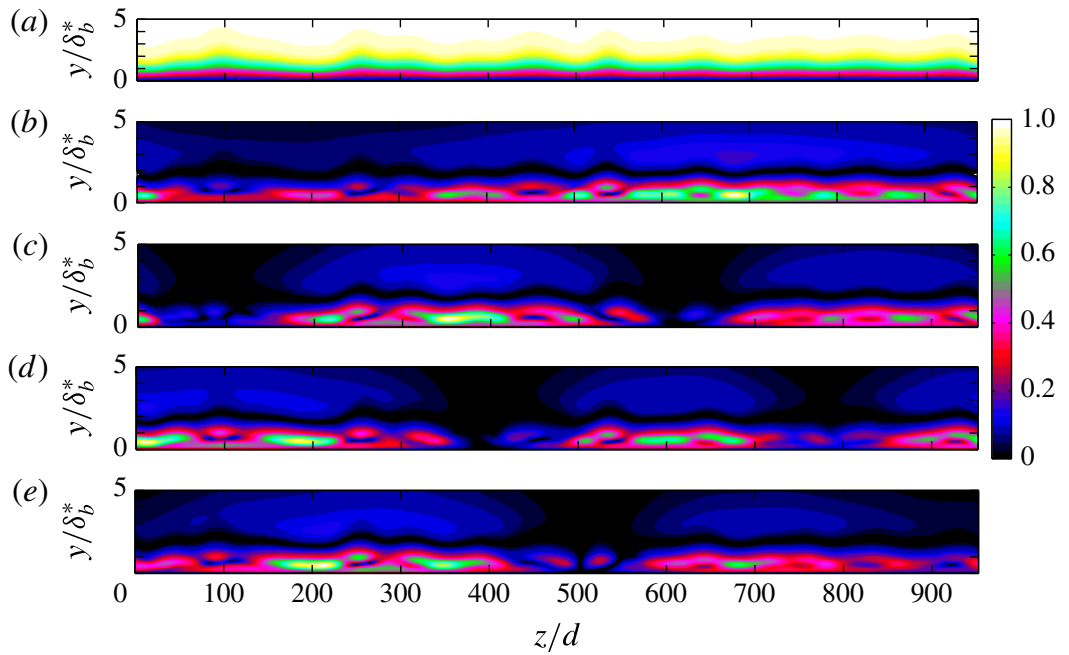

FIGURE 22. (Colour online) (a) Contours of streamwise velocity for the $\beta=50 \%$, $\sigma_{\delta}=0.075$ zither base flow at $R e_{\delta^{*}}=1615(R=940)$. (b) Streaky TS mode, labelled A, $u_{r m s}$. (c) Streaky oblique TS mode, labelled B, $u_{r m s}$. (d) Streaky oblique TS mode, labelled C, $u_{r m s}$. (e) Addition of modes B and C, $u_{r m s}$.

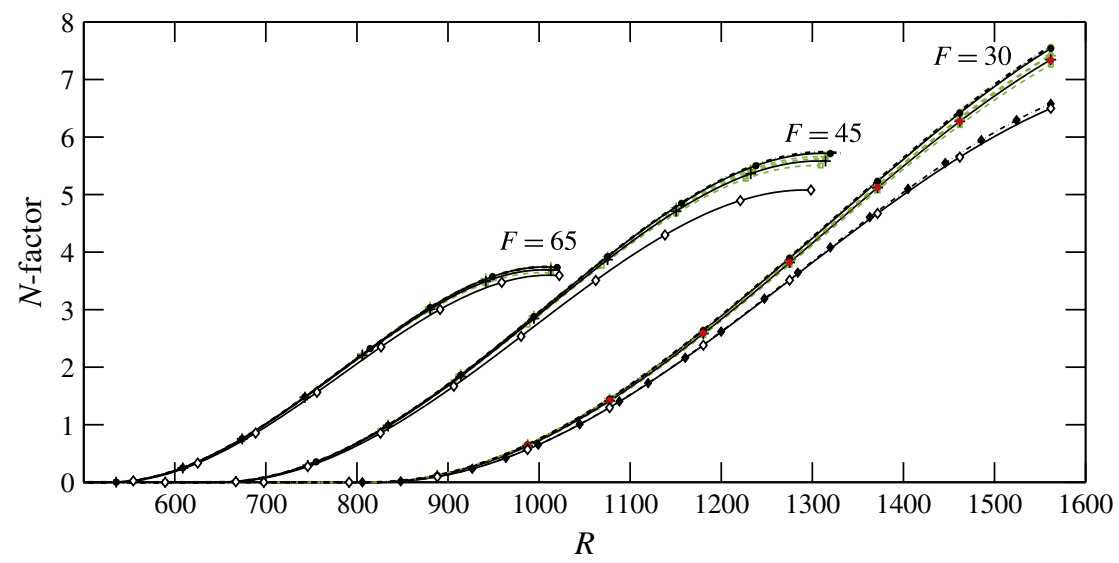

FIgURE 23. (Colour online) $N$-factor curves for the zither streak base flows. Lines: two-dimensional base flow; -.-. $F=30$ disturbance for $\beta=50 \%$ with $\sigma_{\delta}=0.025$ zither CFD base flow with increased mesh resolution; Other lines and markers as for figure 15.

mesh refined in each spatial direction by a factor of 1.5 in the boundary-layer region (total mesh size $\sim 125$ million $\mathrm{CV}, \sim 60 \mathrm{CV}$ across the boundary layer). The mesh refinement modifies the calculated $N$-factor at $R=1550$ by approximately $1 \%$, an inconsequential error for the current level of analysis. Increasing the resolution of the PSE-3D to 95 collocation points and $k=32$ Fourier modes changes the $N$-factor by $0.5 \%$.

The $F=65$ disturbance reaches Branch 2, the streamwise position where the disturbance becomes stable again, just downstream of $R=1000$. The greatest 
suppression of the streaky TS is observed for the $\beta=50 \%$ with $\sigma_{\delta}=0.075$ zither. However, the decrease in the Branch $2 \mathrm{~N}$-factor is only 0.1 .

The $F=45$ TS mode reaches Branch 2 just downstream of $R=1300$ on the twodimensional base flow. At $R=1300$, the standard deviation of streak amplitude $\left(\sigma_{A}\right)$ for the $\beta=50 \%$ with $\sigma_{\delta}=0.075$ zither has reached $7.8 \%$. The greater streamwise extent of TS and streak growth leads to greater suppression. For the $\beta=50 \%$ with $\sigma_{\delta}=0.075$ zither, the reduction in the Branch $2 \mathrm{~N}$-factor is 0.65 . If transition were to occur due to this frequency, $N$-factor $=5$ for the two-dimensional base flow, then the predicted position to reach the same mode amplitude ratio would be delayed from $R=$ 1170 to $R=1250$. For a wind-tunnel velocity of $8.6 \mathrm{~m} \mathrm{~s}^{-1}$ and air, this corresponds to a shift from $x=2.33 \mathrm{~m}$ to $x=2.66 \mathrm{~m}$; a delay of $15 \%$. For the weaker zither streaks, the delay would be less than $3.5 \%$.

The $F=30$ disturbance Branch $2 \mathrm{~N}$-factor is not observed in the streamwise domain. However, the suppression of TS growth is considerable. At $R=1550$, the maximum reduction in $N$-factor is 1 . If transition were to occur due to this frequency for the two-dimensional base flow, $N$-factor $=6.5$ at $R=1470$, then the $\beta=50 \%$ with $\sigma_{\delta}=$ 0.075 zither would reach the same amplitude ratio at $R=1560$. For the stated tunnel conditions, this corresponds to $x=3.68 \mathrm{~m}$ and $x=4.15 \mathrm{~m}$. A delay of nearly $500 \mathrm{~mm}$, or $12.6 \%$. For all other zither wakes, the predicted delay is less than $100 \mathrm{~mm}$, a delay of $2.7 \%$.

The plausibility of a significant shift in the transition location due to a zither more than $2 \mathrm{~m}$ upstream is supported by experimental observations. Watmuff (1998) replaced screens in his wind tunnel and observed a 3-fold reduction in $u_{r m s}$ in the layer, indicating significantly weaker streaks. For this intermediate configuration (further flow quality improvements were made), turbulent bursting was observed to shift from $R \approx 1500$ upstream to $R \approx 1220$. For the two-dimensional layer, this corresponds to a reduction in $N$-factor from $7.3(F=30)$ to $5.4(F=45)$. Assuming transition at $R=1500$ for the $\beta=50 \%$ with $\sigma_{\delta}=0.075$ zither gives an $N$-factor of 6 . Removing the streaks, an $N$-factor of 6 would predict transition at approximately $R=1300$ due to $F=42.5$.

The streak influence on TS-wave secondary instability may be important. Liu, Zaki \& Durbin $(2008 a, b)$ found that increasing streak width would promote the growth of the TS-wave secondary instability and transition, while suppressing growth of the TS wave. However, for TS-wave amplitudes of $1 \%$, streak amplitudes in excess of $13 \%$ were required to destabilise the TS-wave secondary instability. Considering that the zither streaks are weak, and $75-85 \%$ of the pre-transitional region is governed by linear stability theory (Reed, Saric \& Arnal 1996), i.e. TS amplitudes $\lesssim 1 \%$, then the $\mathrm{N}$-factor analysis which describes this region may provide a reasonable transition prediction.

\subsection{Streak secondary instability}

An extensive search for a streak secondary instability of the $\beta=50 \%$ with $\sigma_{\delta}=0.075$ zither streak base flow at $R=1550$ was conducted. The QZ method was used with up to 25 Fourier modes, and the Arnoldi method was used with up to 45 Fourier modes, searching the phase velocity region of $0.6-0.85$. Streak secondary instability is known to occur at these phase velocities (Andersson et al. 2001). No secondary instability was detected. The streaky base flow is still quite weak and for steady streaks, only the results of Vaughan \& Zaki (2011) would suggest a streak secondary instability may be present at the current streak amplitudes. 


\section{Discussion}

\subsection{Zither wakes and jet coalescence}

For the majority of zithers with a uniform inflow, the wake-strength equation of Böttcher \& Wedemeyer (1989) due to the variation of wire position qualitatively captures the wake decay $\left(\bar{x}^{-0.75}\right)$ but under predicts the wake strength. It was hypothesised that variation in wire position would modify wire drag and change the wake decay rate from $\bar{x}^{-0.75}$ towards $\bar{x}^{-0.25}$, producing stronger far wakes. Only the $\beta=50 \%$ with $\sigma_{\delta}=0.075$ zither induced a substantial large-wavelength drag variation that modified the far-wake decay. Velocity contours showed isolated instances of jet deflection, but not as significant as experimental visualisations (comparing contour plots from computations to experimental flow visualisation may be a contributory factor). In the context of the linear diffusion equation, explaining a stronger far wake in terms of the coalescence of jets is problematic. This phenomena occurs over a short wavelength, i.e. the pairing, tripling, etc., of jets is wavelengths of the order of $2 M$. Short wavelengths have no influence on the far wake. Supporting the proposition that the coalescence of jets is not responsible for increased spanwise variation of the test-section layer, is the wire drag data of the $\beta=40 \%$ with $\sigma_{\delta}=0.025$ zither. This zither exhibited a unique Fourier spectrum for drag, with relatively larger coefficients for wavenumbers approaching that for a wavelength $2 M$. Velocity contours revealed more significant instances of jet deflection relative to the $\beta=50 \%$ with $\sigma_{\delta}=0.075$ zither, yet the spanwise variation in the test-section layer was reduced.

Based on the zither simulations, it is hypothesised that for a given open-area ratio, there is a variation in wire position $\left(\sigma_{\delta}\right)$ above which large wavelengths of drag are excited and the far wake will be stronger, e.g. $\sigma_{\delta}=0.075$ for $\beta=50 \%$. Instances of jet deflection may be apparent (a symptom) but it is not a cause. The allowable variation in wire position is likely to be Reynolds-number dependent. Lower Reynolds numbers reduce the change in drag (pressure drop) with changing open-area ratio, thus larger errors in wire position will be required to induce significant variations at lower Reynolds numbers. This may also explain the less substantial jet deflection in the current simulations relative to experimental flow visualisations. Another consideration is that the steady simulations may prevent a flow instability developing that creates a different jet pattern. This would require time-dependent simulations to assess.

Screens may produce wakes in better agreement with the combined wake equation (far wake $\propto \bar{x}^{-0.25}$ ) as there is a variation in drag across the screen where wires intersect. Assuming each intersection has a slightly different drag, then it may be expected that large wavelengths, that most zithers failed to excite, could be present. Experimental measurements of screen wake strength by Böttcher \& Wedemeyer (1989) observed a reduced wake decay beyond $\bar{x} \simeq 1$, for two of the three screens tested. Interestingly, the lowest open-area ratio tested $(\beta=53 \%)$ did not exhibit the wake decay change in the observed domain. The zither simulations would suggest a non-uniform inflow could produce the observed response. However, the experiment towed the screens through a water tank, eliminating non-uniform inflow as a factor.

The zither wakes from a non-uniform inflow showed increasingly stronger far wakes, relative to a uniform inflow, with increasing open-area ratio. The non-uniform inflow with large-wavelength velocity variation induced large-wavelength drag variations and hence, wake decay tending to $\bar{x}^{-0.25}$. However, with decreasing open-area ratio, the drag variation induced becomes near equal and opposite to the contribution of the non-uniform inflow, cancelling out the non-uniform inflow as predicted by Taylor \& Batchelor (1949). The wake of the $\beta=40 \%$ with $\sigma_{\delta}=0.025$ zither was 
near invariant to the non-uniform inflow. This result indicates that low open-area ratio screens should be used to remove flow non-uniformity. However, a physically constructed screen (zither) will have some dimensional error in wire positions $(E)$ introduced by the manufacturing process (say $\sigma_{E}$ ). This will create a wake described by the equation of Böttcher \& Wedemeyer (1989). From (2.17), the wake strength is dependent on the product, $\bar{q}(\operatorname{Re}, \beta) \sigma_{E} / \sqrt{M}$. The mean source strength increases rapidly (nonlinearly) with decreasing open-area ratio (see figure 5.1 of Pook 2013) while $M$ decreases linearly (for a zither) and $\sigma_{E}$ is a constant. Hence, the imperfect, low-open-area ratio zither can have a significantly stronger far wake despite cancelling the non-uniform inflow. The onset of increased wake strength could appear rapidly with a small change in open-area ratio. The non-dimensional standard deviation of position error $\sigma_{\delta}$ will increase and this could further increase the far wake strength if large-wavelength drag variation is induced, as was observed for the $\beta=50 \%$ with $\sigma_{\delta}=0.075$ zither with a uniform inflow. Increased far wake strengths can be ascribed without resorting to the coalescence of jet phenomena.

\subsection{Zither wake through the contraction}

Contractions, while reducing streamwise velocity variation in proportion to the inverse of the contraction ratio, tilt and stretch normal vorticity into streamwise vorticity. The stretching of a 5:1 contraction can cancel out a significant amount of wake decay near the contraction boundaries by converting it to streamwise vorticity. At the measurement location downstream of the contraction, the streamwise vorticity created from normal vorticity was $30-45 \%$ of the normal vorticity entering the contraction. The wake exiting the contraction will be nearly immeasurable in terms of streamwise velocity (largest variation $0.015 \%$ of $U$ ). Boundary layers are most receptive to low-frequency streamwise vorticity (Schrader et al. 2010), and this vortical disturbance can undergo considerable non-modal/algebraic growth in the boundary layer (Andersson et al. 1999; Luchini 2000; Levin \& Henningson 2003). This can create significant spanwise variation of the test-section boundary layer.

\subsection{Streak spacing}

The Böttcher \& Wedemeyer (1989) theory provides an explanation for consistent Klebanoff streak spacing between differing experiments, that is not necessarily seen in simulations that use 'artificial free-stream turbulence'. The wake wavelength is predicted to be independent of zither geometry. This agrees with Matsubara \& Alfredsson (2001) who observed physically constant Klebanoff streak spacing with differing disturbance grids. It also concurs with the results of Swearingen \& Blackwelder (1987), who found that the mean spacing of Görtler vortices was unaffected by changing the screen mesh size or the position of the final settling chamber screen, but the actual spacing pattern was dependent on the individual screen and repeatable. The apparent insensitivity to the screen streamwise location could be attributed to the $x^{0.5}$ dependence of the wake wavelength, combined with large $x$. The wavelength will not change significantly downstream of a moderate or high contraction ratio due to the reduced time for diffusion in the higher-speed flow.

\subsection{Streak amplitude}

The most substantial streaks were created by the $\beta=50 \%$ with $\sigma_{\delta}=0.075$ zither which had the strongest wake. The maximum streak amplitude $(A)$ at $R=1500$ was 
approximately $20 \%$. The standard deviation of streak amplitude $\left(\sigma_{A}\right)$ was $9 \%$. The maximum variation in the layer displacement thickness $\left(\Delta \delta^{*}\right)$ was $70 \%$. The skinfriction variation $\left(\sigma_{c f} / \overline{c f}\right)$ was $17 \%$, of the order measured by Bradshaw (1965) in a turbulent layer and attributed to the coalescence of jets.

Directly relating streak amplitude to a zither, or the zither wake strength upstream of the contraction, was not achieved. The ratio of the standard deviation of streak amplitude to the standard deviation of the wake strength entering the contraction $\left(\sigma_{A} / \sigma_{\Delta u / U i n}\right)$, varied between 4.5 and 10.5 at $R=1500$. Larger open-area ratio zithers and smaller wire position errors $\left(\sigma_{\delta}\right)$ collapsed closely to 4.5. With decreasing open-area ratio and increasing wire position error, this ratio increased. This is attributed to the zither creating stronger, large-wavelength modes due to the increasing variation in drag across the zither. The ratio $\sigma_{A} / \sigma_{\Delta u / U \text { in }}$ will be wind-tunnel dependent.

\subsection{Zither streak linear stability}

PSE-3D computations to calculate an $N$-factor revealed only the $\beta=50 \%$ with $\sigma_{\delta}=0.075$ zither significantly altered TS-wave growth. For $F=30$, the $N$-factor was reduced by 1 in the streamwise domain (Branch 2 was not reached). The $e^{N}$ method would predict a transition shift in excess of $10 \%$. However, the validity of using a spanwise global growth rate to predict and correlate with transition is untested although a greater than $10 \%$ shift in transition due to streaks seems possible (see Watmuff 1998).

All the zither streaks stabilised TS in the streamwise region examined. This is consistent with the behaviour of the optimal streak (Cossu \& Brandt 2004; Bagheri \& Hanifi 2007; Schlatter et al. 2011), steady roughness or vortex generator streaks (Fransson et al. 2005a, 2006; Shahinfar et al. 2012), and Klebanoff streaks (Arnal \& Juillen 1978; Boiko et al. 1994; Watmuff 1998). However, it contrasts the results of Vaughan \& Zaki (2011) for steady streaks generated from the free stream with a Squire mode that increased TS-wave growth rates at low streak amplitudes. The source of the disturbance that generates the streak is important when determining its effect on TS instabilities. Aforementioned experimental results indicate that Klebanoff streaks generated from a screen or grid are stabilising. However, Kendall (1991) has experimentally observed increased TS-wave-packet growth in the presence of Klebanoff streaks generated from a disturbance upstream of the contraction. Work is required to explain the anomalous observations. A secondary streak instability was not detected for the zither streak base flows.

\section{Acknowledgements}

D.A.P. acknowledges funding from the Australian Postgraduate Award (APA). Access to the Trifid HPC cluster provided by the V3 Alliance and the assistance of the RMIT eResearch Office is gratefully acknowledged.

\section{REFERENCES}

Andersson, P., Berggren, M. \& Henningson, D. S. 1999 Optimal disturbances and bypass transition in boundary layers. Phys. Fluids 11 (1), 134-150.

Andersson, P., Brandt, L., Bottaro, A. \& Henningson, D. S. 2001 On the breakdown of boundary layer streaks. J. Fluid Mech. 428, 29-60. 
Arnal, D. \& Juillen, J. C. 1978 Contribution Experimentale a l'etude de la Receptivite d'un Couche Limite Laminaire, a la Turbulence de l'ecoulement General. ONERA Tech. Rep. No. $1 / 5018$ AYD.

BAgheri, S. \& HANifi, A. 2007 The stabilizing effect of streaks on Tollmien-Schlichting and oblique waves: a parametric study. Phys. Fluids 19 (7), 19-22.

Batchelor, G. K. 2000 An Introduction to Fluid Dynamics, 2nd edn. Cambridge University Press.

Bell, J. H. \& MehtA, R. D. 1990 Development of a two-stream mixing layer from tripped and untripped boundary layers. AIAA J. 28 (12), 2034-2042.

Bohl, J. G. E. V. 1940 Das Verhalten paralleler Luftstrahlen. Ing.-Arch. 11 (4), 295-314.

Boiko, A. V., Westin, K. J. A., Klingmann, B. G. B., Kozlov, V. V. \& Alfredsson, P. H. 1994 Experiments in a boundary layer subjected to free stream turbulence. Part 2. The role of TS-waves in the transition process. J. Fluid Mech. 281, 219-245.

Böttcher, J. \& Wedemeyer, E. 1989 The flow downstream of screens and its influence on the flow in the stagnation region of cylindrical bodies. J. Fluid Mech. 204, 501-522.

BRADSHAw, P. 1965 The effect of wind-tunnel screens on nominally two-dimensional boundary layers. J. Fluid Mech. 22 (4), 679-687.

DE BRAY, B. G. 1967 Some investigations into the spanwise non-uniformity of nominally two-dimensional incompressible boundary layers downstream of gauze screens. Aeronautical Research Council $R \& M 3578$.

Broadhurst, M. S. \& Sherwin, S. J. 2008 The parabolised stability equations for 3D-flows: implementation and numerical stability. Appl. Numer. Maths 58 (7), 1017-1029.

Butler, K. M. \& FARrell, B. F. 1992 Three-dimensional optimal perturbations in viscous shear flow. Phys. Fluids A 4 (8), 1637-1650.

Cheng, M. \& Moretti, P. M. 1988 Experimental study of the flow field downstream of a single tube row. Exp. Therm. Fluid Sci. 1 (1), 69-74.

CORRSIN, S. 1944 Investigation of the behavior of parallel two-dimensional air jets. NASA TM 101182.

Cossu, C. \& BRAndT, L. 2002 Stabilization of Tollmien-Schlichting waves by finite amplitude optimal streaks in the blasius boundary layer. Phys. Fluids 14 (8), 1-4.

Cossu, C. \& BRANDT, L. 2004 On Tollmien-Schlichting-like waves in streaky boundary layers. Eur. J. Mech. (B/Fluids) 23 (6), 815-833.

Crow, S. C. 1966 The spanwise perturbation of two-dimensional boundary layers. J. Fluid Mech. 24 (1), 153-164.

Dengel, P. \& Fernholz, H. H. 1989 Generation of and measurements in a turbulent boundary layer with zero skin friction. In Advances in Turbulence (ed. H. H. Fernholz \& H. E. Fiedler), vol. 1, pp. 432-437. Springer.

Deyhle, H. \& Bippes, H. 1996 Disturbance growth in an unstable three-dimensional boundary layer and its dependence on environmental conditions. J. Fluid Mech. 316, 73-113.

Ellingsen, T. \& Palm, E. 1975 Stability of linear flow. Phys. Fluids 18 (4), 487-488.

Ertunç, O., Özyllmaz, N., Lienhart, H., Durst, F. \& Beronov, K. 2010 Homogeneity of turbulence generated by static-grid structures. J. Fluid Mech. 654, 473-500.

Fransson, J. H. M. \& Alfredsson, P. H. 2003 On the disturbance growth in an asymptotic suction boundary layer. J. Fluid Mech. 482, 51-90.

Fransson, J. H. M., Brandt, L., TAlamelli, A. \& Cossu, C. $2005 a$ Experimental study of the stabilization of Tollmien-Schlichting waves by finite amplitude streaks. Phys. Fluids 17 (5), 054110.

Fransson, J. H. M., Matsubara, M. \& Alfredsson, P. H. $2005 b$ Transition induced by free-stream turbulence. J. Fluid Mech. 527, 1-25.

Fransson, J. H. M. \& TAlamelli, A. 2012 On the generation of steady streamwise streaks in flat-plate boundary layers. J. Fluid Mech. 698, 211-234.

Fransson, J. H. M., Talamelli, A., Brandt, L. \& Cossu, C. 2006 Delaying transition to turbulence by a passive mechanism. Phys. Rev. Lett. 96 (6), 064501.

Goldstein, M. E. 2014 Effect of free-stream turbulence on boundary layer transition. Phil. Trans. R. Soc. Lond. A 372 (2020), 20130354. 
Goldstein, M. E. \& Leib, S. J. 1993 Three-dimensional boundary-layer instability and separation induced by small-amplitude streamwise vorticity in the upstream flow. J. Fluid Mech. 246, $21-41$.

Goldstein, M. E., Leib, S. J. \& Cowley, S. J. 1992 Distortion of a flat-plate boundary layer by free-stream vorticity normal to the plate. J. Fluid Mech. 237, 231-260.

GÜRÜN, A. M. 2006 Interactions of Tollmien-Schlichting waves and stationary transient disturbances. $\mathrm{PhD}$ thesis, Case Western University.

HANCOCK, P. E. 1998 Plane multiple screens in non-uniform flow, with particular application to wind tunnel settling chamber screens. Eur. J. Mech. (B/Fluids) 17 (3), 357-369.

Herbert, T. 1988 Secondary instability of boundary layers. Annu. Rev. Fluid Mech. 20, 487-526.

Hultgren, L. S. \& Gustavsson, L. H. 1981 Algebraic growth of disturbances in a laminar boundary layer. Phys. Fluids 24 (6), 1000-1004.

HunT, L. E. 2011 Boundary-layer receptivity to three dimensional roughness arrays on a swept-wing. $\mathrm{PhD}$ thesis, Texas A\&M University.

Jacobs, R. G. \& Durbin, P. A. 2001 Simulations of bypass transition. J. Fluid Mech. 428, 185-212.

KENDALL, J. M. 1985 Experimental study of disturbances produced in a pre-transitional laminar boundary layer by weak freestream turbulence: AIAA-85-1695. In 18th Fluid Dynamics and Plasmadynamics and Lasers Conference, July 16-18, pp. 1-10. AIAA.

KendALl, J. M. 1991 Studies on laminar boundary-layer receptivity to freestream turbulence near a leading edge: FED-VOL. 114. In Boundary Layer Stability and Transition to Turbulence, pp. 23-30. ASME.

Kendall, J. M. 1998 Experiments on boundary-layer receptivity to freestream turbulence: AIAA-980530. In 36th Aerospace Sciences Meeting \& Exhibit, January 12-15, pp. 1-14. AIAA.

Klebanoff, P. S. 1971 Effect of freestream turbulence on a laminar boundary layer. Bull. Amer. Phys. Soc. 10 (11), 1323.

Klebanoff, P. S., Tidstrom, K. D. \& Sargent, L. M. 1961 The three-dimensional nature of boundary-layer instability. J. Fluid Mech. 12, 1-42.

Laws, E. M. \& Livesey, J. L. 1978 Flow through screens. Annu. Rev. Fluid Mech. 10, 247-266.

Le Gal, P., Peschard, I., Chauve, M. P. \& Takeda, Y. 1996 Collective behavior of wakes downstream a row of cylinders. Phys. Fluids 8 (8), 2097-2106.

Leib, S. J., Wundrow, D. W. \& Goldstein, M. E. 1999 Effect of free-stream turbulence and other vortical disturbances on a laminar boundary layer. J. Fluid Mech. 380, 169-203.

Levin, O. \& Henningson, D. S. 2003 Exponential vs algebraic growth and transition prediction in boundary layer flow. Flow Turbul. Combust. 70, 183-210.

LiU, Y., ZAKi, T. A. \& DURbin, P. A. 2008 a Boundary-layer transition by interaction of discrete and continuous modes. J. Fluid Mech. 604, 199-233.

LIU, Y., ZAKI, T. A. \& DURBin, P. A. $2008 b$ Floquet analysis of secondary instability of boundary layers distorted by Klebanoff streaks and Tollmien-Schlichting waves. Phys. Fluids 20 (12), 124102.

Loehrke, R. I. \& Nagib, H. M. 1972 Experiments on management of free-stream turbulence. Tech. Rep. AGARD-R-598.

LUCHINI, P. 2000 Reynolds-number-independent instability of the boundary layer over a flat surface: optimal perturbations. J. Fluid Mech. 404, 289-309.

Matsubara, M. \& Alfredsson, P. H. 2001 Disturbance growth in boundary layers subjected to free-stream turbulence. J. Fluid Mech. 430, 149-168.

MehtA, R. D. 1985 Turbulent boundary layer perturbed by a screen. AIAA J. 23 (9), 1335-1342.

Mehta, R. D. \& Bradshaw, P. 1979 Design rules for small low speed wind tunnels. Aeronaut. J. 73, 443-449

Mehta, R. D. \& Hoffmann, P. H. 1987 Boundary layer two-dimensionality in wind tunnels. Exp. Fluids 5 (5), 358-360. 
Morgan, P. G. 1960 The stability of flow through porous screens. J. R. Aero. Soc. 64, 359-362; (June).

Morkovin, M. V. 1979 Observations on streamwise vortices in laminar and turbulent boundary layers. NASA CR 159061.

Nolan, K. P. \& Walsh, E. J. 2012 Particle image velocimetry measurements of a transitional boundary layer under free stream turbulence. J. Fluid Mech. 702, 215-238.

Ovchinnikov, V., Choudhari, M. M. \& Piomelli, U. 2008 Numerical simulations of boundarylayer bypass transition due to high-amplitude free-stream turbulence. J. Fluid Mech. 613, $135-169$.

PATEl, R. P. 1964 The effects of wind tunnel screens and honeycombs on the spanwise variation of skin friction in two-dimensional turbulent boundary layers. Tech. Rep. T/N 64-7, McGill University.

Pook, D. A. 2013 The origin and effects of free-stream vortical disturbances on boundary layer transition in wind tunnels. PhD thesis, RMIT University.

Pook, D. A. \& Watmuff, J. H. 2014 Streak generation in wind tunnels. Phys. Fluids 26 (7), 073605.

Reddy, S. C., Schmid, P. J. \& Henningson, D. S. 2008 Pseudospectra of the Orr-Sommerfeld operator. SIAM J. Appl. Maths 53 (1), 15-47.

ReED, H. L., SARIC, W. S. \& ARNAL, D. 1996 Linear stability theory applied to boundary layers. Annu. Rev. Fluid Mech. 28, 389-428.

Ricco, P. 2009 The pre-transitional Klebanoff modes and other boundary-layer disturbances induced by small-wavelength free-stream vorticity. J. Fluid Mech. 638, 267.

Ricco, P., LuO, J.\& WU, X. 2011 Evolution and instability of unsteady nonlinear streaks generated by free-stream vortical disturbances. J. Fluid Mech. 677, 1-38.

SCHEIMAN, J. \& BROOKS, J. D. 1981 Comparison of experimental and theoretical turbulence reduction characteristics for screens, honeycomb, and honeycomb-screen combinations. AIAA J. 18 (8), 638-643.

Schlatter, P., Deusebio, E., De Lange, R. \& Brandt, L. 2011 Numerical study of the stabilisation of boundary-layer disturbances by finite amplitude streaks. Tech. Rep. Swedish e-Science Research Centre, Linne FLOW Centre, KTH Mechanics, Stockholm, Sweden.

SChmid, P. J. 2007 Nonmodal stability theory. Annu. Rev. Fluid Mech. 39, 129-162.

Schrader, L.-U., Brandt, L., Mavriplis, C. \& Henningson, D. S. 2010 Receptivity to freestream vorticity of flow past a flat plate with elliptic leading edge. J. Fluid Mech. 653, 245-271.

SChrader, L.-U., BrAndT, L. \& ZAKi, T. A. 2011 Receptivity, instability and breakdown of Görtler flow. J. Fluid Mech. 682, 362-396.

Schubauer, G. B., Spangenberg, W. G. \& Klebanoff, P. S. 1950 Aerodynamic characteristics of damping screens. NACA TN 2001.

Shahinfar, S., Sattarzadeh, S. S. \& Fransson, J. H. M. 2014 Passive boundary layer control of oblique disturbances by finite-amplitude streaks. J. Fluid Mech. 749, 1-36.

Shahinfar, S., Sattarzadeh, S. S., Fransson, J. H. M. \& Talamelli, A. 2012 Revival of classical vortex generators now for transition delay. Phys. Rev. Lett. 109 (7), 074501.

SWEARIngen, J. D. \& BlackWElder, R. F. 1986 Spacing of streamwise vortices on concave walls. AIAA J. 24 (10), 1706-1709.

SWEARINGen, J. D. \& BLACKWELDER, R. F. 1987 The growth and breakdown of streamwise vortices in the presence of a wall. J. Fluid Mech. 182, 255-290.

TAN-Atichat, J., Nagib, H. M. \& Loehrke, R. I. 1982 Interaction of free-stream turbulence with screens and grids: a balance between turbulence scales. J. Fluid Mech. 114, 501-528.

TAYlor, G. I. \& BAtChelor, G. K. 1949 The effect of wire Gauze on small disturbances in a uniform stream. Q. J. Mech. Appl. Maths 2 (1), 1-27. 
Vaughan, N. J. \& ZAKI, T. A. 2011 Stability of zero-pressure-gradient boundary layer distorted by unsteady Klebanoff streaks. J. Fluid Mech. 681, 116-153.

WAtmufF, J. H. 1998 Detrimental effects of almost immeasurably small freestream nonuniformities generated by wind-tunnel screens. AIAA J. 36 (3), 379-386.

WAtMufF, J. H. 2006 Effects of weak free stream nonuniformity on boundary layer transition. Trans. ASME J. Fluids Engng 128 (2), 247-257.

Westin, K. J. A., Boiko, A. V., Klingmann, B. G. B., Kozlov, V. V. \& Alfredsson, P. H. 1994 Experiments in a boundary layer subjected to free stream turbulence. Part 1. Boundary layer structure and receptivity. J. Fluid Mech. 281, 193-218.

Wu, X., Zhao, D. \& Luo, J. 2011 Excitation of steady and unsteady Görtler vortices by free-stream vortical disturbances. J. Fluid Mech. 682, 66-100.

Wundrow, D. W. \& Goldstein, M. E. 2001 Effect on a laminar boundary layer of small-amplitude streamwise vorticity in the upstream flow. J. Fluid Mech. 426, 229-262.

ZAKI, T. A. 2013 From streaks to spots and on to turbulence: exploring the dynamics of boundary layer transition. Flow Turbul. Combust. 91 (3), 451-473. 